University of Zurich

Department of Economics

Working Paper Series

ISSN 1664-7041 (print)

ISSN 1664-705X (online)

Working Paper No. 359

\title{
Public Discourse and Socially Responsible Market Behavior
}

Björn Bartling, Vanessa Valero, Roberto A. Weber and Lan Yao

August 2020 


\title{
Public Discourse and Socially Responsible Market Behavior ${ }^{*}$
}

\author{
Björn Bartling Vanessa Valero Roberto A. Weber Lan
}

August 18, 2020

\begin{abstract}
We investigate the causal impact of public discourse on socially responsible market behavior. We conduct laboratory market experiments with products that differ in their production costs and social impact, and provide market actors and impacted third parties with the opportunity to discuss appropriate market behavior. Across two studies that vary characteristics of the discourse, the external impact and the participants, we find that public discourse substantially increases market social responsibility. Our findings suggest that discussions and campaigns focusing on appropriate market behavior can be powerful tools for shaping responsible norms governing market conduct and addressing inefficiencies due to market failures.
\end{abstract}

JEL Classification: C92, D62, D83, M14

Keywords: Public discourse, market failure, externalities, social responsibility, social norms, experiment, communication

\footnotetext{
* Bartling/Weber: Department of Economics, University of Zurich, Blümlisalpstrasse 10, 8006 Zurich, Switzerland; Valero: School of Business and Economics, Loughborough University; Yao: Shanghai University of Finance and Economics. We are grateful for support from the Swiss National Science Foundation (grant number 100018_165943) and for helpful comments from Ernst Fehr, Roland Bénabou, Florian Schneider and participants at several seminars and conferences.
} 


\section{Introduction}

The production, exchange and consumption of a good can create negative impacts on parties uninvolved in the market transaction. For example, markets for fossil fuels, weapons and animalbased products are often highlighted as instances where exchange between parties that benefit from a transaction can have substantial detrimental impacts on others. Standard prescriptions for such problems - such as bans or taxation-are sometimes infeasible due to the complexity of determining optimal policy and political inertia. As an alternative remedy, there are many calls for market actors, including firms and consumers, to exhibit social responsibility and voluntarily internalize the externalities generated by their market activities (Bénabou and Tirole, 2010). However, the mechanisms through which consumers and firms can actually be encouraged to incur greater personal costs in order to benefit others remains in need of better understanding.

One possible channel for fostering socially responsible behavior is through public discourse and campaigns. By highlighting the harmful societal impacts of specific forms of market exchange and drawing attention to the actions that may mitigate such harm, individuals' perceptions of appropriate conduct and the social norms governing market exchange might be altered to encourage greater social responsibility. For example, the "Fridays for Future" movement aims to stimulate discussions regarding the negative environmental impacts of carbon emissions and encourages consumers, firms and policymakers to change their behavior. ${ }^{1}$ Responsible consumption in pursuit of climate change mitigation is also widely discussed in the media, on university campuses and in policy forums. For example, the World Economic Forum dedicates a substantial amount of its activities to discussions and publications on the topic of how firms and consumers can take actions to mitigate climate change. ${ }^{2}$ Other large public campaigns advocate voluntary avoidance of single-use plastics, fur, pesticides and animal testing. However, whether such campaigns have any impact on the behavior of market participants remains unexplored. A better understanding of whether public discourse can affect socially responsible market behavior and improve societal outcomes is thus necessary.

In this paper, we report two laboratory studies that explore the causal effect of public discourse on market social responsibility. Both of our studies involve stylized product markets in which products that vary in their social impact are traded between market participants in the roles

\footnotetext{
${ }^{1}$ See https://fridaysforfuture.org/ (accessed on August 4, 2020)

2 See https://www.weforum.org/agenda/archive/climate-change (accessed on August 4, 2020).
} 
of buyers and sellers. In our first experiment, the external impact of market exchange falls on subjects in the role of passive third parties, while in our second experiment the impact is on donations to a charity with the objective of mitigating climate change and reducing poverty. In both experiments, sellers and buyers can exchange either a harmful type of product that costs less to produce but creates external harm or a responsible product that involves a higher production cost but imposes no external harm. We thus measure market social responsibility by the extent to which market actors exchange the responsible product type.

Our experimental manipulations focus on the impact of public discourse-an opportunity for people involved with and impacted by the market to engage in communication. In all cases, this discourse consists of a single 8-minute electronic chat in which participants can repeatedly send messages to all other participants involved in the communication. Our interest is in how this discourse leads to norms and agreements regarding the "correct" thing to do in the market and influences the prevalence of socially responsible exchange.

While a considerable body of experimental research — which we review in the next section-documents that communication generally increases pro-social behavior and efficiency, this literature typically studies instances in which the agreements reached and norms developed benefit all communicating parties and yield Pareto improvements. In our case, by contrast, and in the contexts of most public discourse about limiting the harm from market activity, people who advocate for socially responsible market behavior in public discourse are often promoting actions that are personally costly in monetary terms rather than beneficial. Therefore, it is an open question whether communication is an effective means in such contexts to mitigate social harm, or if selfserving arguments that can arise in such discussions may actually reduce social concern.

In our first study, in which the external impact falls on other, passive study participants in the role of third parties, our treatments vary who participates in the discourse and what the participants know about their role in the market at the time of engaging in discourse. Our first condition, Veil, represents an idealized form of communication in which everyone-buyers, sellers and third parties - participates in the discourse and in which all participants are unaware of their role in the market at the point in time when discourse occurs. Given that all participants are equally likely ex ante to be in the role of third parties, concerns based on self-interest, efficiency and fairness coincide and we expect discourse to highlight "responsibilizing narratives" that advocate for socially responsible behavior by market actors (Bénabou et al., 2019). While such a Rawlsian 
"veil of ignorance" is unrealistic outside the laboratory, this condition represents a potential upper bound for the effects of discourse on socially responsible market behavior and the kind of influence we might expect if individuals could put aside their personal interests at the critical point at which they develop norms regarding appropriate behavior.

Our second condition, No Veil, implements one change by informing participants of their role in the market prior to their engaging in discourse. This represents a more realistic case and, correspondingly, we expect a reduction in the degree of socially responsible behavior. Thus, we test whether the availability of self-interested perspectives concurrent with public discourse changes how such discourse affects behavior and norms governing market conduct.

Our third condition, Exclusive, restricts communication only to the buyers and sellers, who are aware of their roles as in No Veil, omitting the third parties impacted by the externality. Discussions of how to engage in more socially responsible market behavior often occur between members of high-income countries and involve firms and consumers whose conduct creates the externalities - e.g., at the World Economic Forum—with less participation from those people who bear the external costs, such as people in low-income countries. This condition allows us to investigate the importance of participation in discourse by those impacted by negative externalities. Excluding such perspectives and arguments may decrease empathy toward the harm imposed on third parties (Andreoni and Rao, 2011) and may allow market participants to more easily develop "absolving narratives," or self-serving justifications for trading the more harmful and less costly product type (Bénabou et al., 2019). Therefore, we expect the elimination of those harmed by the externality from public discourse to further reduce social responsibility.

Finally, to investigate whether public discourse serves as a complement to or substitute for existing concerns for social impact, we study the impact of discourse in two populations where earlier work found different levels of baseline market social responsibility. In Bartling et al. (2015), market experiments conducted in Switzerland demonstrated substantially higher market shares for the responsible product than identical experiments conducted in China. Public discourse might be complementary to baseline social concern if a sufficient number of socially responsible individuals are needed to promote arguments in support of reducing negative externalities in order to effect change in the remaining market participants. In contrast, public discourse might be a substitute for baseline social concern if the pre-existing high levels of such concern, as in Switzerland, reflect widespread norms regarding appropriate social conduct, leaving little room to further strengthen 
such norms. Therefore, we test whether the impact of discourse differs between the two locations to provide evidence on the importance of existing norms of market conduct.

The results of our first study are striking. First, public discourse in the Veil condition has very large, positive and sustained effects on market social responsibility. In Switzerland, discourse essentially yields almost universal exchange of the responsible product, compared to a market share of about 50 percent in a Baseline condition absent public discourse. Perhaps even more interesting, eliminating the veil of ignorance or excluding third parties from the discourse reduces the impact of discourse on the market share for the responsible product only moderately, if at all. Thus, we find that even a one-time instance of public discourse regarding appropriate market behavior can have profound and persistent impacts on the manifestation of market social responsibility. Using an incentivized norm elicitation method (Krupka and Weber, 2013), we also observe that this impact leads to stronger prescriptive norms regarding the inappropriateness of exchanging the harmful product.

Turning to the interaction between pre-existing levels of social concern and public discourse, we first closely replicate the observation in Bartling et al. (2015) of a lower baseline market share for the responsible product in China than in Switzerland. We interpret this as reflecting weaker prescriptive social norms regarding trade of the socially responsible product in China, which our social norm measurement confirms. However, the positive effects of public discourse on market social responsibility are generally similar between the two populations. For example, the market share of the responsible product increases by roughly 50 percentage points from the Baseline to the Veil condition in both populations. Our findings thus suggest that the effects of public discourse are neither substitutes nor complements, but rather independent of the baseline level of norms governing market conduct.

Our second study is substantively similar but changes two important features. First, we investigate whether discourse has similarly positive effects when the impacts of market exchange are not borne by other similar participants in the laboratory. The laboratory may be an environment in which high levels of social proximity and strong norms of equality make arguments about showing concern for impacts on other laboratory subjects quite strong. In non-laboratory markets, however, negative externalities typically involve more complex consequences that are more socially and psychologically distant. To investigate whether a less laboratory-centered external impact reduces the positive influence of discourse on market social responsibility, we change the 
target of the externality to a charity that works to mitigate climate change and economic inequality by employing farmers in low-income countries to plant trees. Aside from being a more complex and distant influence, using a charity of this kind also creates the possibility that laboratory participants can more easily come up with arguments during discourse for why the charity may be ineffective or undeserving (see Exley, 2020). Despite the substantial design change, our first two conditions, Baseline (Charity) and Exclusive (Charity), essentially replicate the results from the Baseline and Exclusive conditions (since the charity is absent from the discourse) in our first study.

The second change in Study 2 deals with the timing of the public discourse. In all of our other conditions, discourse occurs at the beginning of the experiment, before participants have had an opportunity to engage in market exchange. However, many situations of interest, like climate change, involve contexts in which market behavior already exists and produces negative external impacts. Therefore, it is plausible that increasing social responsibility may be more difficult in such contexts, where historical practices may create greater inertia and a desire to advance arguments in support of existing conduct. Our Experienced (Charity) condition therefore introduces discourse only after several rounds of the baseline market activity. We find that the positive impact of public discourse is similar, irrespective of whether discourse occurs before the market activity, as in Exclusive (Charity), or after participants have experience in trading, as in Experienced (Charity). Thus, our second study reproduces the main substantive finding from our first study and demonstrates the finding's robustness to situations designed to make the positive impacts of discourse more challenging.

To summarize, across two studies and a total of eight comparisons, we find that a simple form of public discourse greatly increases socially responsible market behavior and strengthens the corresponding norms governing market conduct. Our results are important, as they suggest that there is room for these kinds of campaigns and initiatives as a policy tool for promoting efficiency and avoiding negative externalities imposed on third parties. Our results also address the literature on the positive social impacts of communication. In particular, we provide, to our knowledge, the first evidence that allowing people to communicate leads to agreements on behavior that yield higher social surplus in markets, despite the fact that such behaviors are costly to the people engaging in communication. 
The remainder of the paper proceeds as follows. Section 2 reviews related work. Section 3 presents the experimental design and results of Study 1, while Section 4 contains Study 2. Section 5 presents a combined analysis of the content of discourse from both studies. Section 6 concludes.

\section{Related Literature}

Our research closely relates to a growing body of work that investigates the conditions under which individuals choose to voluntarily internalize the external impacts of their market activity (Rode et al., 2008; Bénabou and Tirole, 2010; Dufwenberg et al., 2011; Bartling et al., 2015, 2019, 2020; Hainmueller et al. 2015; Kirchler et al., 2015; Pigors and Rockenbach, 2016; Irlenbusch and Saxler, 2019; Danz et al., 2020; Ockenfels et al. 2020; Sutter et al., 2020). As with our work, much of this research uses laboratory experiments, which have the advantage of allowing tight control of the market environment and the establishment of causal relationships. While questions about external validity always need to be carefully considered, recent work indicates that preferences for more socially responsible products in the laboratory predict willingness to pay more for such products in real product markets (Engelmann et al., 2018). Our work is novel to this literature, since no earlier papers study the effects of communication and discourse on socially responsible market behavior.

Perhaps even closer to our work, numerous studies demonstrate that communication can be efficiency enhancing in other domains of social behavior, such as in social dilemmas (Dawes et al., 1977; Isaac and Walker, 1988; Ostrom et al., 1992; Bochet et al., 2006), in coordination games (Cooper et al., 1992; Blume and Ortmann, 2007; Brandts and Cooper, 2007; Kriss et al., 2016) and under incomplete contracting (Charness and Dufwenberg, 2006; Kessler and Leider, 2012; Krupka et al., 2017). In all these papers, providing individuals with the opportunity to communicate generally means that they act more cooperatively or coordinate their actions better, making all communicating parties better off. While this suggests that we may similarly observe more efficient outcomes with fewer externality-producing products when we introduce discourse in our market experiments, there is an important distinction. In our experiment, discourse only improves efficiency if it convinces buyers and sellers to incur greater personal monetary costs to benefit others impacted by their market behavior-participants in the role of third parties (Study 1) or a charity (Study 2). Thus, relative to the above work, our study is unique in investigating whether communication can lead to more pro-social, but personally monetarily costly, actions. 
Only one other paper experimentally investigates how communication affects decision making in contexts where efficiency involves lower earnings for decision makers. Ellman and Pezanis-Christou (2010) study two-person laboratory firms with varying hierarchical structures, where production entails a bad that generates profits for the firm but harms a third party. Their treatments manipulate communication between a manager and a subordinate. They find that communication has a positive impact on socially responsible behavior, lowering the negative externality, but only under a vertical structure in which the manager decides on a production level and the employee can decide whether to implement this action or quit. Thus, the findings suggest that communication can facilitate greater pro-social concerns toward outsiders. However, the extent to which such an effect would survive in a market context, involving many other participants, with repeated interactions and diffused responsibility, is unclear. Bartling et al. (2015) find that pro-social behavior in market contexts differs from similar behavior framed as a nonmarket interaction, which suggests that findings generated in non-market contexts might not necessarily translate into market contexts.

A separate line of research studies how communication influences distributional outcomes, as in dictator or bargaining games. For instance, Agranov and Tergiman (2014) study communication in a Baron-Ferejohn bargaining context, where one individual makes a proposal regarding how to divide a fixed pie and a majority of committee members have to approve the proposal for it to be implemented. Communication produces proposals closer to the theoretical prediction of minimum-winning coalitions that typically reward coalition members and exclude others entirely, suggesting that communication can be employed to produce more favorable outcomes for a few, at the expense of others with less strategic power. In our experiments, this suggests that discourse may lead to outcomes that advantage the buyers and sellers at the expense of the third parties, which is clearly inconsistent with our data.

In other related work, Andreoni and Rao (2011) study communication in dictator games, finding that the presence and nature of communication has strong impacts on one-sided sharing. Specifically, when only the recipient or both the dictator and the recipient can send messages, giving increases; but when only the dictator can send messages, the amount shared decreases. Andreoni and Rao interpret these effects as resulting from communication from the recipient increasing empathy, but communication only from the dictator providing excuses or rationalizations for sharing less. In our experiments, this suggests that excluding those impacted 
by the externality from discourse may decrease social responsibility, perhaps even to levels below those in the no-communication baseline, which is not supported by our data. While we find that the positive impact of discourse sometimes decreases when impacted third parties are excluded from discourse, the difference is not consistently statistically significant. Moreover, we find that socially responsible behavior is more prevalent, relative to the no communication baseline, even when impacted third parties are excluded from discourse.

\section{Study 1}

We implement an experimental product market in which subjects in the roles of sellers and buyers can trade two types of products. One product type generates a negative externality for third parties but has a low cost of production. The other type has a higher production cost but does not impose any social harm. Our main interest is the market share of the latter, socially responsible, product type. We give participants in some treatments the opportunity to discuss appropriate market behavior before they start interacting in the market, which allows us to study the impact of public discourse on social responsibility. We study two distinct subject pools, a student sample from Zurich, Switzerland and a student sample from Shanghai, China.

\subsection{Experimental Design}

\subsubsection{Market Game}

A market comprises 16 participants: six firms, five consumers and five third parties. Roles are randomly assigned and remain fixed throughout the experiment.

Markets are repeated for 24 periods. At the beginning of a period, each subject receives an initial endowment of 100 points. Firms and consumers can earn additional points from their market transactions. Two types of products exist that differ only in their negative impact on the third parties and their production cost. One product type-which we refer to as the "fair product"-is socially responsible, meaning that it does not produce a negative externality, but costs 10 to produce. The other product type - the "harmful product" — creates a negative externality of 60 for third parties, but costs nothing to produce. Both products have a value of 50 to a consumer, meaning that the two product types differ only in their social impact.

In each period, firms simultaneously select product types and prices (between 0 and 50) in a posted-offer market. Once all firms make their decisions, the resulting offers are publicly 
revealed to all consumers. ${ }^{3}$ Consumers enter the market sequentially in an order that is randomly determined in each period and decide whether to buy at most one product. Consumers thus observe a menu of up to six product offers, each consisting of a price and a product type. Each firm earns, in case its offered product is sold, the difference between the posted price and the production cost. Each consumer earns, if he or she decides to buy a product, the difference between the product's value of 50 and the price paid.

Third parties can neither sell nor buy, but they can incur losses depending on the types of products exchanged. In every period, third parties and consumers are randomly matched into pairs. If a consumer purchases a harmful product, then the randomly matched third party incurs a loss of 60. If the consumer purchases a fair product or does not purchase any product, then the randomly matched third party does not incur a loss.

The extent to which the market produces the fair product is a reflection of the degree of social responsibility exhibited by firms and consumers. We use the market share of the fair product as our primary measure of social responsibility.

\subsubsection{Treatments}

In our Baseline condition, there is no discourse prior to engaging in the market activity. Subjects directly proceed to the market game after learning their roles as firm, consumer or third party.

We implement three treatment conditions that include public discourse. These add an 8minute interval during which subjects have the opportunity to communicate via an electronic chat window. We provide guidance for the public discourse by asking subjects to discuss how "socially acceptable" or "socially inacceptable" it is to trade the product with negative impact on third parties and to what extent trading this product is consistent or inconsistent with what most people agree is the "appropriate," "right” or "moral" thing to do. The messages are not restricted, other than proscribing personally identifying, obscene or insulting statements.

Table 1 provides an overview of our treatments. In the Veil condition, subjects engage in public discourse prior to learning their roles as firms, consumers or third parties. That is, subjects in this condition discuss the appropriateness and moral acceptability of exchanging a product with negative impact on third parties behind a Rawlsian "veil of ignorance.” In contrast, in the No Veil

\footnotetext{
${ }^{3}$ We eliminate the possibility of cross-period reputation by not showing subjects the identification numbers of other market participants and by randomly ordering the display of product offers in each period.
} 
condition, we inform subjects of their roles prior to engaging in the public discourse. Apart from the timing of information about subjects' roles, the Veil and No Veil conditions are identical. ${ }^{4}$ Finally, in the Exclusive condition, we inform subjects of their roles prior to engaging in the public discourse, as in No Veil. But in contrast to No Veil, only firms and consumers participate in the discourse in the Exclusive condition. This feature prevents third parties from communicating their concerns and recommendations regarding market behavior. ${ }^{5}$

Table 1: Overview of Experimental Conditions

\begin{tabular}{ccccc}
\hline \hline & Baseline & Veil & No Veil & Exclusive \\
\hline$t=1$ & - & $\begin{array}{c}\text { Public discourse } \\
\text { (all roles) }\end{array}$ & - & - \\
\hline$t=2$ & & Subjects learn their roles: firm, consumer or third party \\
\hline$t=3$ & - & - & $\begin{array}{c}\text { Public discourse } \\
\text { (all roles) }\end{array}$ & $\begin{array}{c}\text { Public discourse } \\
\text { (excl. third parties) }\end{array}$ \\
\hline$t=4$ & \multicolumn{4}{c}{ Subjects participate in the market for 24 periods } \\
\hline \hline
\end{tabular}

\subsubsection{Social Norm Elicitation}

In all treatments, we elicit social norms at the end of the market, using the elicitation method developed by Krupka and Weber (2013). We use this task to elicit participants' ratings of the social appropriateness of trading the harmful product. Subjects can choose from four possible responses: "highly socially acceptable,” "somewhat socially acceptable,” "somewhat socially inacceptable," and "highly socially inacceptable," to describe such behavior. Subjects' responses are incentivized: each participant earns additional money (CHF 10 in Switzerland or CNY 10 in China) if that subject's response corresponds to the most frequently chosen answer provided by the other subjects in a session.

\footnotetext{
${ }^{4}$ Subjects can refer to each other during the chat through fixed ID numbers. Messages are preceded by identifiers ranging from 1-16 in Veil and by letter-number combinations (e.g., "S1" through "S6" for sellers) that also identify roles in No Veil. However, they cannot subsequently match messages to individual market behavior.

${ }^{5}$ We also give the third parties the possibility to discuss among themselves in order to engage all subjects during the eight minutes of public discourse. All subjects are aware of this design feature. However, the discourse among the third parties cannot directly affect the market outcome because third parties are passive players.
} 


\subsubsection{Procedures}

We conducted the study at the University of Zurich and the Shanghai University of Finance and Economics. We collected eight markets per treatment, both in Switzerland and in China, with each market consisting of 16 participants (six sellers, five buyers and five third parties). A total of 1,024 subjects participated in the above four experimental conditions, half of them in Switzerland and half of them in China. We implemented the experiment using z-Tree (Fischbacher, 2007). When entering the lab, subjects received written instructions and had to answer control questions to ensure understanding of the market activity. ${ }^{6}$

Experimental points in the market game were converted into money at the rate of 10 points to CHF 2.50 in Switzerland and CNY 4 in China. The relative conversion rates aim at matching the purchasing power of experimental points in both countries. One period was randomly chosen for payment at the end of a session. On average, subjects in China earned about CNY 62, including a show-up fee of CNY 15; subjects in Switzerland earned about CHF 41, including a show-up fee of CHF 15. Sessions lasted about two hours, on average.

\subsection{Hypotheses}

We assume that individuals not only care about their earnings in the market but also- to different degrees-about the negative externalities generated by the market activity. The more the individuals care about the social impact of their market activity, i.e., the higher their levels of social responsibility, the higher the market share of the fair product. For example, such concern can be captured by a representative utility function of the form, $u=\pi(x)-\theta s(x)$, where the first term on the right hand side corresponds to an individual's pecuniary payoff from exchanging product $x$ and the second term represents the potential disutility from exchanging a product that produces social harm, $s(x)$. The term, $\theta$, captures the weight individuals place on the externality. The higher this weight in a population, the larger the market share of the fair product. Bartling, et al. (2015) find that a simple utility function of this type captures behavior in the market experiment quite well and estimate $\theta>0$ across several experimental treatments.

\footnotetext{
${ }^{6}$ To ensure comparability between the two sets of instructions, we employed a back-translation procedure in writing the Mandarin version of the instructions - one person translated the English instructions into Mandarin and another person translated them back into English to identify and reconcile inconsistencies. The English version of the instructions for Study 1 is in Appendix F.
} 
Extending this approach to our experiment, let the weight placed on the externality be given by $\theta\left(\gamma_{s}, d_{t}\right)$. The first argument, $\gamma_{s} \geq 0$, denotes the pre-existing (or intrinsic) level of social concern that prevails in a society, with $s=\{$ Switzerland, China $\}$ in our study. The second argument, $d_{t}$, captures how the weight depends on the type of public discourse, with $t=$ $\{\varnothing$, Veil, No Veil, Exclusive $\} . \theta\left(\gamma_{s}, d_{\varnothing}\right)$ thus denotes the weight placed on negative externalities in a given society in the absence of any opportunities to engage in public discourse, as in our Baseline condition.

We first compare the market share of the fair product in Baseline and Veil. We expect that engaging in discourse behind a Rawlsian veil of ignorance when subjects know that they might be in the role of a third party will increase concern for social impact by highlighting arguments for efficiency and by enhancing empathy for the third parties. Our hypothesis H1 captures that we expect a positive effect of discourse on the weight placed on the negative externality in Veil, and thus a higher market share of the fair product, relative to Baseline.

$$
\text { H1: } \theta\left(\gamma_{s}, d_{V e i l}\right)>\theta\left(\gamma_{s}, d_{\emptyset}\right)
$$

Our second set of hypotheses deal with the impact of discourse on social concern as we add more realistic features to the discourse. First, people are typically aware of their roles in society. When buyers and sellers know their roles-as beneficiaries of low-cost production-we expect that they will be less inclined to generate and less easily swayed by appeals to social responsibility. This is captured in our hypothesis H2a. Second, public discourse in high-income countries often involves consumers and producers from such countries but omits those individuals in other, often low-income, countries affected by the externalities. We expect that eliminating participation in discourse by those impacted by externalities will further diminish the extent to which public discourse enhances concerns for efficiency and empathy. This is captured in our hypothesis $\mathrm{H} 2 \mathrm{~b}$.

$$
\begin{gathered}
\text { H2a: } \theta\left(\gamma_{s}, d_{\text {Veil }}\right)>\theta\left(\gamma_{s}, d_{\text {No Veil }}\right) \\
\text { H2b: } \theta\left(\gamma_{s}, d_{\text {No Veil }}\right)>\theta\left(\gamma_{s}, d_{\text {Exclusive }}\right)
\end{gathered}
$$

Note that we do not provide hypotheses for comparisons of our Baseline condition with either No Veil or Exclusive, because the results could go either way. For instance, public discourse in No Veil may enhance concern for social impact through similar channels as in Veil-by promoting concerns for efficiency or empathy for third parties. However, market participants may 
also use the communication opportunity to generate self-serving justifications for benefitting by trading the socially harmful product. Thus, the net effect could possibly yield higher or lower levels of social responsibility in No Veil compared to Baseline. Moreover, even if concern for social impact is higher in No Veil than in Baseline, whether concern for social impact remains higher in Exclusive, once third parties are excluded from discourse, is not clear a priori. While we refrain from stating directional hypotheses, we will study how market shares of the fair product in Baseline compare with those in both No Veil and Exclusive, as an exploratory question.

Finally, our comparison of treatment effects in Switzerland and China allow us to investigate how pre-existing levels of social concern interact with public discourse. Bartling et al. (2015) found that market actors in the Baseline condition in China exhibit substantially lower concern for mitigating negative externalities than those in Switzerland. We expect to replicate the finding in our Baseline treatment, that is, $\theta\left(\gamma_{\text {Switzerland, }}, d_{\emptyset}\right)>\theta\left(\gamma_{\text {China }}, d_{\varnothing}\right)$.

If the finding replicates, we can investigate whether public discourse has a differential effect in a population with a low level of initial social concern (China) and one with a high level of social concern (Switzerland). Pre-existing levels of social concern and public discourse could be complements - this would be the case if a critical mass of baseline social concern is needed to produce compelling arguments for socially responsible behavior that sway the actions of market actors who would otherwise trade the harmful product. Alternatively, it could also be that baseline levels of social concern and public discourse are substitutes. For example, the high level of baseline social concern in Switzerland might leave little room to further strengthen norms of social responsibility, while the absence of such strong norms in China might create greater opportunity for developing them through public discourse. We thus investigate whether

$$
\left[\theta\left(\gamma_{\text {Switzerland }}, d_{t}\right)-\theta\left(\gamma_{\text {Switzerland }}, d_{\varnothing}\right)\right] \lesseqgtr\left[\theta\left(\gamma_{\text {China }}, d_{t}\right)-\theta\left(\gamma_{\text {China }}, d_{\varnothing}\right)\right] .
$$

We do not make any assumptions about the nature of this relationship but study it as an exploratory question.

\subsection{Results}

In this section, we focus on market behavior in Study 1, to evaluate the impact of public discourse and study how public discourse influences social norms. We defer analysis of the content of the discourse to Section 5, where we conduct the analysis jointly for our two studies. 


\subsubsection{Public Discourse Behind the Veil of Ignorance}

The two leftmost bars in the top panel of Figure 1 show the market shares of the fair product, our measure of social responsibility, in Baseline and Veil in Switzerland. The bottom panel shows the data for China. ${ }^{7}$

Figure 1: Market Shares of the Fair Product

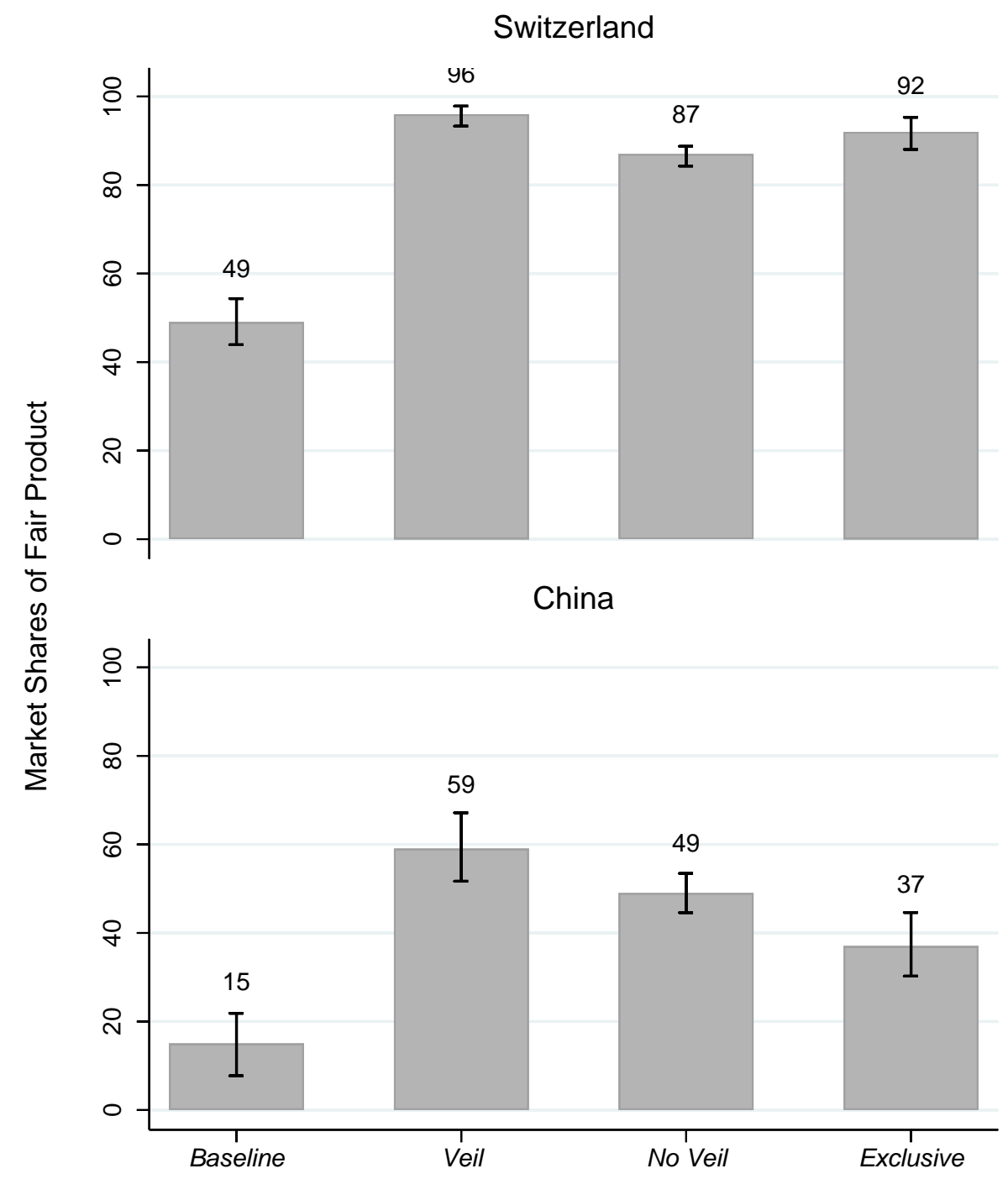

Notes: The figure shows completed transactions and ignores the cases in which a consumer did not purchase a product. The bars indicate standard errors of the mean at the market level.

\footnotetext{
${ }^{7}$ We exclude the 2.3 percent of cases in Switzerland and 3.5 percent of cases in China in which buyers did not make a purchase, thereby imposing no loss on third parties. Including these cases and counting them as socially responsible behavior does not substantively change our results.
} 
The figure reveals that social responsibility increases substantially in both countries when market actors engage in public discourse behind the veil of ignorance prior to trading in the market. The market share of the fair product in Switzerland is about 50 percent in the Baseline condition, but rises to almost 100 percent in Veil. ${ }^{8}$ Turning to the data from China, we find that the Baseline market share of the fair product is only 15 percent, much lower than in Switzerland. ${ }^{9}$ However, the market share of the fair product almost quadruples to about 60 percent in Veil. Wilcoxon ranksum tests at the market (consumer) level indicate that the difference between Baseline and Veil is statistically significant in both countries; $\mathrm{p}=0.001(\mathrm{p}<0.001)$ for Switzerland and $\mathrm{p}=0.005$ ( $\mathrm{p}<0.001)$ for China. ${ }^{10}$ The data thus provide clear support for hypothesis H1 in both countries. ${ }^{11}$

Result 1: Public discourse behind the veil of ignorance increases socially responsible market behavior.

\subsubsection{Less Idealistic Forms of Public Discourse}

Our first discourse condition, Veil, implements the Rawlsian ideal of discourse behind the veil of ignorance and provides a potential upper bound for the effects of public discourse on socially responsible market behavior. Our second discourse condition, No Veil, deviates from the Rawlsian ideal: participants know their roles in the market prior to engaging in discourse.

Figure 1 reveals that the market share of the fair product is reduced when the veil of ignorance is removed prior to public discourse, from 96 to 87 percent in Switzerland and from 59 to 49 percent in China. Wilcoxon rank-sum tests indicate that the differences between Veil and No Veil are statistically significant at the market (consumer) level in Switzerland, $\mathrm{p}=0.014(\mathrm{p}=0.001)$, but not in China, $\mathrm{p}=0.248$ ( $\mathrm{p}=0.145)$. Hypothesis 2a is thus supported in Switzerland but not in China.

\footnotetext{
${ }^{8}$ Figure A.1 in Appendix A shows that the fair-product market shares are generally stable across periods. Figure A.2 shows the empirical cumulative distributions of fair-product market shares by treatment in both countries.

${ }^{9}$ The design of the Baseline condition in this paper is identical to the Baseline condition in Bartling et al. (2015), which also studied the same two populations. The market shares of the fair product in our Baseline conditions closely replicate the market shares in Bartling et al., both in Switzerland (44 and 48 percent across two studies) and China (16 percent).

${ }^{10}$ Appendix Table A.1 provides p-values for all pairwise treatment comparisons. All Wilcoxon rank-sum tests reported in this paper are two-sided.

${ }^{11}$ The mean prices of the fair and harmful products are 29 and 24, respectively, in the Baseline in Switzerland. The respective prices in Veil are 29 and 21. Socially responsible buyers and sellers who trade the fair product thus share the additional cost of production. The same holds in China, where we observe similar average prices for the fair and harmful product: 25 and 22, respectively, in the Baseline and 28 and 21, respectively, in Veil.
} 
Our third discourse condition, Exclusive, restricts participation in the discourse to buyers and sellers, thereby excluding the perspectives and arguments of those impacted by negative externalities. The rightmost bars in Figure 1 show the market share of the fair product in this condition. The figure illustrates that the market share of the fair product slightly increases in Switzerland (from 87 to 92 percent) but further decreases in China (from 49 to 37 percent). However, Wilcoxon rank-sum tests at the market (consumer) level indicate that the differences between No Veil and Exclusive are not consistently statistically significant; $\mathrm{p}=0.140$ ( $\mathrm{p}=0.049$ ) for Switzerland and $\mathrm{p}=0.293$ ( $\mathrm{p}=0.055$ ) for China. Thus, Hypothesis $2 \mathrm{~b}$ is not supported in Switzerland and is directionally, but not statistically, supported in China. ${ }^{12}$

Result 2: (a) The positive impact of public discourse on socially responsible market behavior tends to be slightly weaker when individuals discuss in front of rather than behind the veil of ignorance. (b) Excluding negatively affected third parties from public discourse, on top of removing the veil of ignorance, does not substantially weaken its positive impact.

While we refrained from stating hypotheses regarding the impact of discourse in No Veil and Exclusive relative to our Baseline condition, Wilcoxon rank-sum tests indicate that the market share of the fair product is significantly higher in No Veil and Exclusive than in Baseline, both in Switzerland and China, irrespective of whether we test at the market or consumer level $(p=0.001$ in all tests in Switzerland and $\mathrm{p} \leq 0.027$ in all tests in China).

Observation 1: Public discourse increases socially responsible market behavior even when individuals discuss in front of the veil of ignorance and even when negatively affected third parties are excluded from the discourse.

As a complement to the above non-parametric tests, Table 2 reports random-effects generalized least squares regressions with consumers' product choices-i.e., whether a consumer buys a fair or harmful product in a period —as dependent variable. ${ }^{13}$ The Baseline condition serves as the omitted category. We include binary treatment variables, Veil, No Veil and Exclusive, which

\footnotetext{
${ }^{12}$ The prices of the fair and harmful products in No Veil and Exclusive are very similar to the respective prices in Baseline and Veil. The fair product trades at 29, on average, in both conditions in Switzerland and the harmful product trades at 23 and 20, respectively. The same holds for China. The fair product trades at 27, on average, in both conditions and the harmful product trades at 20 and 22, respectively.

${ }^{13}$ We report the results of Probit regressions in Table A.2 in Appendix A.
} 
take on value 1 in the respective treatment and 0 otherwise. To evaluate the impact of discourse in general, we create the variable Discourse taking on value 1 in all three discourse treatments and 0 otherwise. We include the general Discourse variable in models (3) and (6). In models (2), (3), (5) and (6) we control for time effects by including the variable Period, taking on integer values between 1 and 24, and the interactions of the treatment variables with Period. Models (1), (2) and (3) present results for Switzerland and models (4), (5) and (6) for China.

Looking first at models (1) and (2) for Switzerland, the coefficients for Veil, No Veil and Exclusive are positive, substantially large in magnitude, and significant at the one percent level in both models. This indicates large, positive treatment effects of all public discourse treatments, which do not vary over time. Turning to China, model (4) again finds the level effects of discourse to be positive and statistically significant, although Exclusive is statistically significant only at the five percent level. In model (5), the interaction Period $\times$ Exclusive is positive and significant at the five percent level, while the coefficient for Exclusive is not statistically significant, indicating that the effect of discourse on socially responsible behavior develops over time in this condition in China. These results confirm our earlier results based on non-parametric Wilcoxon rank-sum tests. ${ }^{14}$ The positive and statistically highly significant coefficients for Discourse in models (3) and (6) indicate the general tendency in our data for all forms of discourse to increase socially responsible market behavior. ${ }^{15}$

\footnotetext{
${ }^{14}$ The coefficients for Veil are consistent with the earlier stated results regarding H1 in both countries. Post-estimation tests of equality of the coefficients for Veil and No Veil in models (1) and (4) fail to reject equality in China but not in Switzerland; see p-values in Table A.3 in Appendix A. Post-estimation tests of equality of the coefficients for No Veil and Exclusive fail to reject equality in both countries.

${ }^{15}$ As an excursus, we also investigate a general methodological point relevant for understanding the impact of discourse and communication in experimental studies. One possible interpretation of the effect of providing participants with the opportunity to engage in public discourse is that the effect is due to communication itself, i.e., due to the exchange of messages. However, two changes result from introducing the option to communicate: first, subjects can exchange messages and, second, subjects are prompted and provided with the time to reflect on the topic about which they are communicating. In the case of our experiment, even if subjects did not actively engage in communication, the 8-minute discourse interval might also influence the choices they subsequently make by prompting them to think about appropriate market behavior. To provide insights into this distinction, we conducted a post hoc treatment in which we ask individuals to spend eight minutes reflecting and composing statements regarding appropriate market behavior, but these are not shared with other market participants. This Reflection condition increases market social responsibility relative to the Baseline. However, we also find that the effect of discourse extends beyond the effects of reflection in Switzerland, but not in China. Therefore, part of the impact of communication, and a great part of it in our experiment in China, seems to be driven by asking people to reflect on their behavior (see also Krupka and Weber, 2009). This finding suggests a role for public campaigns that do not actually require people to engage in communication, but instead simply ask them to consider their behavior. To conserve space, and given the tangential and post hoc nature of this part of our investigation, we report the details of the design and results of our Reflection condition in Appendix B.
} 
Table 2: Random-effects GLS regressions of fair consumer product choice

\begin{tabular}{|c|c|c|c|c|c|c|}
\hline & \multicolumn{3}{|c|}{ Switzerland } & \multicolumn{3}{|c|}{ China } \\
\hline & (1) & (2) & (3) & (4) & (5) & (6) \\
\hline Veil & $\begin{array}{c}0.457^{* * *} \\
(0.057)\end{array}$ & $\begin{array}{c}0.416 * * * \\
(0.067)\end{array}$ & & $\begin{array}{c}0.446^{* * * *} \\
(0.100)\end{array}$ & $\begin{array}{c}0.450 * * * \\
(0.111)\end{array}$ & \\
\hline No Veil & $\begin{array}{c}0.371^{* * *} \\
(0.055)\end{array}$ & $\begin{array}{c}0.436 * * * \\
(0.067)\end{array}$ & & $\begin{array}{c}0.342 * * * \\
(0.079)\end{array}$ & $\begin{array}{c}0.419 * * * \\
(0.102)\end{array}$ & \\
\hline Exclusive & $\begin{array}{c}0.424^{* * *} \\
(0.061)\end{array}$ & $\begin{array}{c}0.382 * * * \\
(0.077)\end{array}$ & & $\begin{array}{c}0.244^{* *} \\
(0.093)\end{array}$ & $\begin{array}{c}0.151 \\
(0.121)\end{array}$ & \\
\hline Discourse & & & $\begin{array}{c}0.412 * * * \\
(0.065)\end{array}$ & & & $\begin{array}{c}0.341^{* * *} \\
(0.098)\end{array}$ \\
\hline Period & & $\begin{array}{l}-0.003 \\
(0.002)\end{array}$ & $\begin{array}{l}-0.003 \\
(0.002)\end{array}$ & & $\begin{array}{c}-0.004^{* *} \\
(0.002)\end{array}$ & $\begin{array}{c}-0.004^{* *} \\
(0.002)\end{array}$ \\
\hline Period $\times$ Veil & & $\begin{array}{c}0.003 \\
(0.003)\end{array}$ & & & $\begin{array}{l}-0.000 \\
(0.005)\end{array}$ & \\
\hline Period $\times$ No Veil & & $\begin{array}{l}-0.005 \\
(0.004)\end{array}$ & & & $\begin{array}{l}-0.006 \\
(0.005)\end{array}$ & \\
\hline Period $\times$ Exclusive & & $\begin{array}{c}0.003 \\
(0.003)\end{array}$ & & & $\begin{array}{c}0.007^{* *} \\
(0.004)\end{array}$ & \\
\hline Period $\times$ Discourse & & & $\begin{array}{c}0.000 \\
(0.003)\end{array}$ & & & $\begin{array}{c}0.000 \\
(0.003)\end{array}$ \\
\hline Constant & $\begin{array}{c}0.484^{* * *} \\
(0.051)\end{array}$ & $\begin{array}{c}0.533 * * * \\
(0.061)\end{array}$ & $\begin{array}{c}0.533 * * * \\
(0.061)\end{array}$ & $\begin{array}{c}0.149 * * \\
(0.067)\end{array}$ & $\begin{array}{c}0.203^{* * * *} \\
(0.084)\end{array}$ & $\begin{array}{c}0.203^{* * *} \\
(0.084)\end{array}$ \\
\hline Observations & 3770 & 3770 & 3770 & 3705 & 3705 & 3705 \\
\hline Subjects & 160 & 160 & 160 & 160 & 160 & 160 \\
\hline
\end{tabular}

Notes. The dependent variable in all models takes on value 1 if a buyer purchased a fair product and 0 if the buyer purchased a harmful product. We omit the cases in which consumers purchased no product. Baseline serves as omitted category. Period takes on integer values between 1 and 24. Discourse takes on value 1 in Veil, No Veil and Exclusive, and 0 otherwise. Standard errors (in parentheses) are clustered at the market level, $* * * \mathrm{p}<0.01, * *$ $\mathrm{p}<0.05, * \mathrm{p}<0.1$.

\subsubsection{Public Discourse and Pre-Existing Social Concern}

The substantially different Baseline levels of social responsibly in Switzerland and China allow us to investigate the interaction of public discourse and pre-existing levels of social concern. Are they substitutes or complements? Table 3 reports random-effects GLS regressions using the pooled data from both countries. ${ }^{16}$ The dependent variable is the choice of the fair product. Baseline in Switzerland serves as omitted category. The large and highly significant coefficients for the four

\footnotetext{
16 The coefficient estimates of random-effects Probit regressions are reported in Table A.4 in Appendix A.
} 
treatment variables in model (1) confirm our earlier findings for Switzerland. The large, negative and highly significant coefficient for China confirms the lower level of socially responsible behavior in the Baseline condition in China than in Switzerland, as shown in Figure 1, replicating the pattern reported in Bartling et al. (2015).

Table 3: Random-effects GLS regressions of fair consumer product choice

\begin{tabular}{|c|c|c|}
\hline & (1) & (2) \\
\hline Veil & $\begin{array}{c}0.457 * * * \\
(0.056)\end{array}$ & \\
\hline No Veil & $\begin{array}{c}0.371^{* * *} \\
(0.055)\end{array}$ & \\
\hline Exclusive & $\begin{array}{c}0.424 * * * \\
(0.061)\end{array}$ & \\
\hline Discourse & & $\begin{array}{c}0.417^{* * *} \\
(0.053)\end{array}$ \\
\hline China & $\begin{array}{c}-0.344 * * * \\
(0.084)\end{array}$ & $\begin{array}{c}-0.344^{* * *} \\
(0.084)\end{array}$ \\
\hline China $\times$ Veil & $\begin{array}{l}-0.010 \\
(0.114)\end{array}$ & \\
\hline China $\times$ No Veil & $\begin{array}{c}-0.029 \\
(0.096)\end{array}$ & \\
\hline China $\times$ Exclusive & $\begin{array}{l}-0.180 \\
(0.111)\end{array}$ & \\
\hline China $\times$ Discourse & & $\begin{array}{c}-0.073 \\
(0.094)\end{array}$ \\
\hline Constant & $\begin{array}{c}0.494^{* * *} \\
(0.051)\end{array}$ & $\begin{array}{c}0.494 * * * \\
(0.051)\end{array}$ \\
\hline Observations & 7,475 & 7,475 \\
\hline Subjects & 320 & 320 \\
\hline
\end{tabular}

Notes. Baseline in Switzerland serves as omitted category. All standard errors (in parentheses) are clustered at the market level, ${ }^{* * *} \mathrm{p}<0.01,{ }^{* *} \mathrm{p}<0.05,{ }^{*} \mathrm{p}<0.1$.

To test whether the effect of public discourse on social responsibility interacts with preexisting levels of concern for social impact, we interact the binary treatment variables with the country indicator China. The coefficients for China $\times$ Veil and China $\times$ No Veil in model (1) are very small and not statistically significant, indicating that entering into public discourse under these conditions has the same impact in Switzerland and China. The coefficient for China $\times$ Exclusive indicates, if anything, that public discourse without the involvement of potential victims of market activities has a smaller impact in China than in Switzerland, but this coefficient is not 
statistically significant. The coefficient for China $\times$ Discourse in model (2), where Discourse takes on value 1 in all three discourse treatments and 0 otherwise, is consistent with the results from model (1) suggesting that the impact of public discourse is similar in Switzerland and China. The effect of public discourse on market social responsibility thus does not seem to depend on preexisting levels of market social responsibility.

Observation 2: The positive effect of public discourse on socially responsible market behavior is independent of the pre-existing level of social concern.

\subsubsection{Social norms}

We next study the social norms we elicited regarding trading of the unfair product in our experimental markets. We collected ratings of the perceived social appropriateness of trading the harmful product, using the measure introduced by Krupka and Weber (2013). Subjects provided ratings of either "highly inappropriate" $(-1)$, "somewhat inappropriate" $(-1 / 3)$, "somewhat appropriate" (1/3) or "highly appropriate" (1) and were incentivized to provide the modal rating given by others.

Figure 2 shows mean social appropriateness ratings by condition and country. The left panel shows the appropriateness ratings in Switzerland, while the panel on the right shows the ratings in China. First, comparing the social appropriateness ratings in Switzerland and China, the figure reveals that imposing social harm in the market is generally perceived as more appropriate in China than in Switzerland. In China, imposing harm on third parties is even considered slightly socially appropriate in the Baseline condition. Second, the figure reveals that ratings of the appropriateness of harmful market behavior are lower in all the discourse conditions, both in Switzerland and China, indicating that public discourse and subsequent market experience yield stronger norms prescribing socially responsible market behavior. ${ }^{17}$

Table 4 reports the results of OLS regressions of the social norm ratings. Models (1) and (2) show, respectively, the results for Switzerland and China. The coefficients for Veil, No Veil, and Exclusive in Study 1 are all negative and statistically significant, both in China and Switzerland, indicating that when subjects engage in public discourse, they subsequently evaluate trading the harmful product as less socially appropriate. ${ }^{18}$

\footnotetext{
${ }^{17}$ Interestingly, the impact of thinking in private about social responsibility in our additional Reflection condition produces an effect on social norms in China, but not in Switzerland (see Appendix B).

${ }^{18}$ The results of ordered Probit regressions are reported in Table A.5 in Appendix A.
} 
Figure 2: Effect of Public Discourse on Social Norms

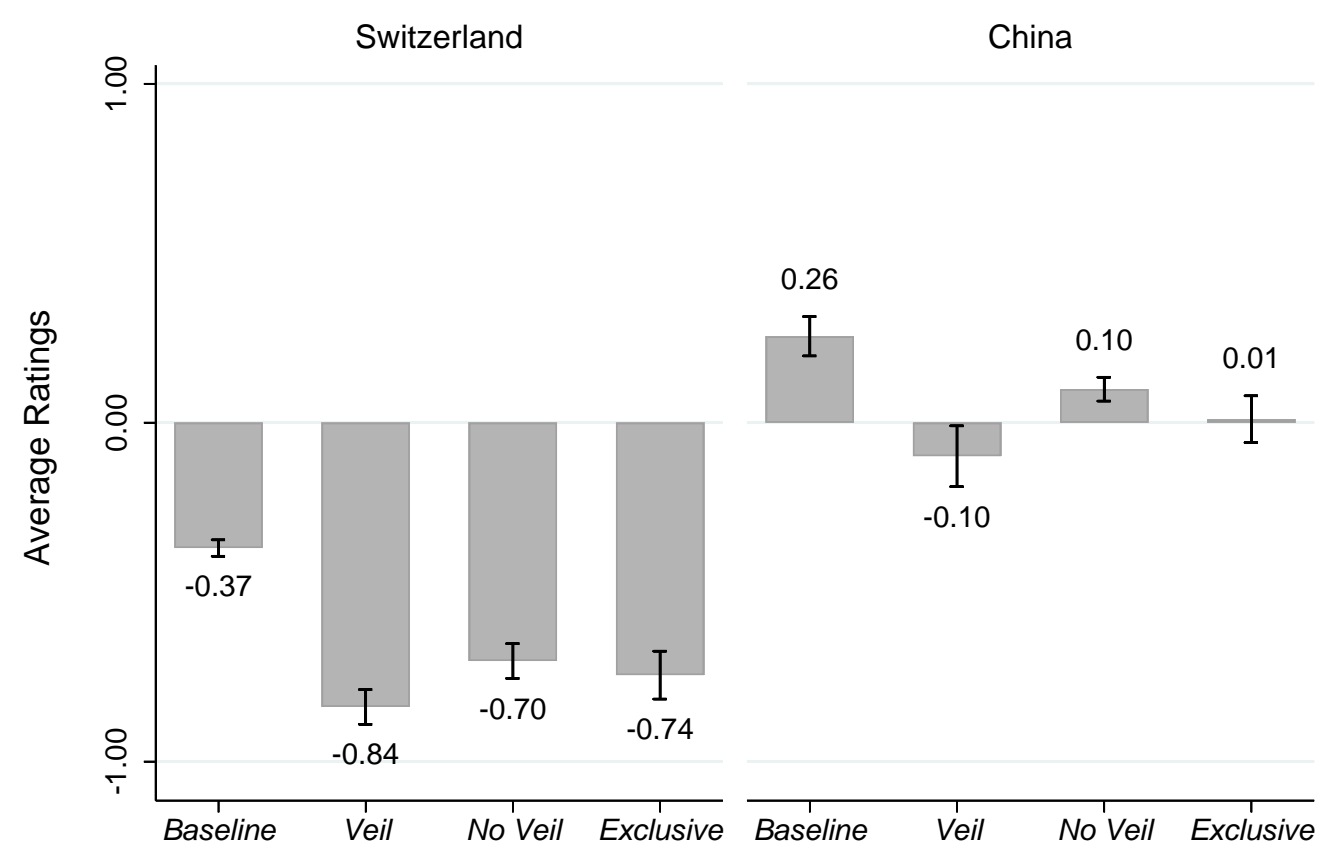

Notes. The figure shows the average rating of the appropriateness of exchanging the harmful product. "Highly Appropriate = 1," "Somewhat Appropriate = 1/3," "Somewhat Inappropriate = $-1 / 3$," "Highly Inappropriate $=-1$." The numerical rating values follow Krupa and Weber (2013). The bars show the standard error of the mean at the market level.

Table 4: OLS regressions of social appropriateness ratings

\begin{tabular}{lcc}
\hline \hline & Switzerland & China \\
& $(1)$ & $(2)$ \\
\hline Veil & $-0.469^{* * *}$ & $-0.354^{* * *}$ \\
No Veil & $(0.054)$ & $(0.102)$ \\
& $-0.333^{* * *}$ & $-0.156^{* *}$ \\
Exclusive & $(0.054)$ & $(0.065)$ \\
& $-0.375^{* * *}$ & $-0.245^{* * *}$ \\
Constant & $(0.071)$ & $(0.086)$ \\
& $-0.370^{* * *}$ & $0.255^{* * *}$ \\
\hline Observations & $(0.023)$ & $(0.055)$ \\
\hline \hline
\end{tabular}

Notes. The dependent variable in all models takes values from -1 to 1 corresponding to the scores previously described. Baseline serves as omitted category. All standard errors (in parentheses) are clustered at the market level, ${ }^{* * *} \mathrm{p}<0.01,{ }^{* *} \mathrm{p}<0.05,{ }^{*} \mathrm{p}<0.1$. 


\section{Study 2}

Study 1 shows that various forms of public discourse substantially increase socially responsible market behavior. These effects obtain in two independent samples, which differ in their preexisting levels of social concern.

In this section, we investigate the robustness of our main qualitative result that public discourse increases socially responsible market behavior. It is important to consider whether particular features of laboratory experiments, which may not be present outside the laboratory, might exaggerate the positive impact of public discourse on market social responsibility.

For instance, the fact that the external effect falls on another experimental subject, who differs from market actors only in a random draw of roles, might make the related earnings inequalities particularly salient and clearly resolvable in the context of the experiment. In contrast, market externalities in most non-laboratory contexts typically involve external impacts on more distant individuals, as well as impacts that are not as easily quantifiable or remediable. In such contexts, discourse about the "right" thing to do might be more nuanced and may facilitate opposing arguments. In Study 2, therefore, we change the impact of the externality to affect, rather than another experimental subject, a charity committed to fighting climate change and poverty in low-income countries.

Moreover, public debate outside the laboratory about appropriate market behavior typically occurs after people have a history of interactions in the relevant market and have developed behaviors that produce a negative externality. This could be important because changing established behavior might be particularly challenging, thus mitigating the impact that public discourse can have on promoting social responsibility, or perhaps even leading to rationalizations for existing behavior that further depress social responsibility. Market actors may have developed habits, strive to behave in a consistent way, or not want to change their behaviors because this would be an acknowledgement that past behaviors were not "appropriate." In Study 2, we thus examine whether public discourse still has a positive effect when it is introduced only after firms and consumers have already traded for several periods in our experimental market.

\subsection{Experimental Design}

A market in Study 2 comprises 11 subjects: six firms and five consumers. At the beginning of every period, each participant receives an initial endowment of 100 points. In addition, we allocate 
each market with a 500-point donation (corresponding to 100 points for each consumer) to the charitable organization “Carbon Offsets To Alleviate Poverty,” which funds programs fighting climate change and poverty in low-income countries (see https://cotap.org/). 100 points correspond to CHF 25 (about USD 25).

Subjects can earn additional points from their market transactions. As in Study 1, they can exchange two types of products that differ in their impact on the COTAP charity. If a firm and a consumer exchange the fair product (or no product at all), then there is no reduction of the donation. But if a product with a negative external impact is exchanged, then the donation is reduced by 60 . While the harmful product costs nothing to produce, the fair product's production cost is 20. Both types of products have the identical value of 50 to a consumer.

As in Study 1, firms simultaneously select product types and prices (between 0 and 50) in a posted-offer market. Once all firms make their choices, consumers enter the market sequentially and decide whether to buy at most one product. If a firm sells its offered product, it earns the difference between price and production cost. If a consumer decides to buy a product, he or she earns the difference between the value of 50 and the price. If a consumer buys a harmful product, the donation is reduced from 100 to 40. If the consumer buys a fair product or no product at all, the donation is unaffected. The market game is repeated for 24 periods. One period is randomly drawn at the end of a session to determine payments.

We implement three different treatment conditions. In Baseline (Charity), subjects directly proceed to the market game after learning their roles as firm or consumer, as in Baseline in Study 1. In Exclusive (Charity), the market game is preceded by 8 minutes of public discourse, in which firms and consumers have the opportunity to discuss the appropriateness of exchanging the harmful product without participation by those impacted by the externality, as in the Exclusive condition of Study 1. We also vary the point in time when market actors engage in discourse in Study 2. Experienced (Charity) is identical to Exclusive (Charity), except that firms and consumers have the possibility to communicate only after having played the first eight periods of the market game ("Part I"). They then continue interacting in the market for the remaining 16 periods ("Part II”). ${ }^{19}$ Table 5 provides an overview of the sequence of events in all conditions in Study $2 .{ }^{20}$

\footnotetext{
${ }^{19}$ For consistency, all conditions in Study 2 included "Part I" and "Part II." In Baseline (Charity) and Exclusive (Charity), the experiment continued in Part II as before.

20 The instructions for Study 2 are in Appendix G.
} 
Table 5: Overview of Experimental Conditions in Study 2

\begin{tabular}{lccc}
\hline \hline & Baseline (Charity) & Exclusive (Charity) & Experienced (Charity) \\
\hline$t=1$ & - & Public discourse & - \\
\hline$t=2$ & & Subjects play the market game for 8 periods ("Part I") \\
\hline$t=3$ & - & - & Public discourse \\
\hline$t=4$ & Subjects play the market game for 16 periods ("Part II”) \\
\hline \hline
\end{tabular}

We conducted the study at the University of Zurich, following the same procedures as in Study 1 . We collected 16 markets per treatment, with each market consisting of 11 subjects, such that a total of 528 subjects participated. In all conditions, we elicit social norms at the end of the market, using the same elicitation method as in Study 1.

\subsection{Hypotheses}

Based on the results of Study 1, we expect public discourse to again have a positive effect on market social responsibility, even when those impacted by the externality do not participate.

$$
\text { H3: } \theta\left(\gamma_{s}, d_{\text {Exclusive (Charity) }}\right)>\theta\left(\gamma_{s}, d_{\text {Baseline }(\text { Charity })}\right)
$$

However, the Exclusive versus Baseline comparison in Study 2 is not a direct replication of these treatments in Study 1, due to the distinct impact of the externality on a charity rather than on other experimental subjects. Therefore, as we note earlier, there are compelling reasons to expect no positive impact of public discourse, or even a negative impact, in such a setting.

Conditional on there being a positive impact of Exclusive (Charity) in Study 2, we expect that the positive impacts of discourse will be weaker when participants have a history of engaging in exchange that yields negative externalities and a desire to rationalize or continue with their preexisting behavior.

$$
\text { H4: } \theta\left(\gamma_{s}, d_{\text {Exclusive (Charity) }}\right)>\theta\left(\gamma_{s}, d_{\text {Experienced (Charity) }}\right)
$$

Finally, whether or not Experienced (Charity) ends up at higher, equal or lower levels of market social responsibility than Baseline (Charity) is a research question for which we have no $a$ priori predictions. 


\subsection{Results}

Figure 3 shows market share of the fair product across periods in all three treatments. The Baseline (Charity) condition shows a steady market share of approximately 50 percent throughout all 24 periods. When market actors enter into public discourse before interacting in the market, in the Exclusive (Charity) condition, the market share of fair products increases to 79 percent. Wilcoxon rank-sum tests at the market (consumer) level indicate that the difference in the average market share of the fair product between Baseline (Charity) and Exclusive (Charity) is statistically significant; $\mathrm{p}=0.002(\mathrm{p}<0.001)$. This supports Hypothesis 3 and qualitatively replicates the finding in Study 1 that public discourse increases socially responsible behavior, even when it involves only those individuals who exchange in the market and personally benefit from exchanging the harmful product.

Result 3: Public discourse increases socially responsible market behavior, even when the negative impact of the externality falls on a charity that is not represented in the discourse.

We next examine whether the positive impact of public discourse is weaker if market participants have experience in trading in the market prior to engaging in discourse. Figure 3 reveals that the market share of the fair product in Experienced (Charity) increases substantially from levels around 60 percent at the end of Part I, which is conducted before the public discourse takes place, to levels around 80 percent in Part II, after public discourse. Wilcoxon rank-sum tests at the market (consumer) level confirm that the average market shares of the fair product are different in Parts I and II (63 percent vs. 79 percent) in Experienced (Charity); p=0.041 ( $\mathrm{p}<0.001$ ). The finding that public debate is effective even when market actors have prior experience in the market is corroborated by the observation that the market shares of the fair product in Part II in No Veil (Charity) and Experienced (Charity), which differ only in whether public discourse took place either prior or subsequent to Part I, are almost identical, 76 percent vs. 79 percent, and not significantly different in Wilcoxon rank-sum tests at the market (consumer); $\mathrm{p}=0.568$ (0.357). ${ }^{21}$

\footnotetext{
${ }^{21}$ We observe an increase of the market share of the fair product between Parts I and II in Experienced (Charity) despite the fact that the market share of the fair product in Part I is already high (63 percent), relative to Baseline (Charity) (50 percent). Wilcoxon rank-sum tests at the market (consumer) level show that the difference in Part I is statistically (marginally) significant; $\mathrm{p}=0.083$ (0.036), despite the fact that the instructions and procedures in Baseline (Charity) and Experienced (Charity) are identical up to the end of Part I.
} 
Observation 3: Public discourse increases socially responsible market behavior even with experienced market participants.

Figure 3: Market Shares of the Fair Product in Study 2

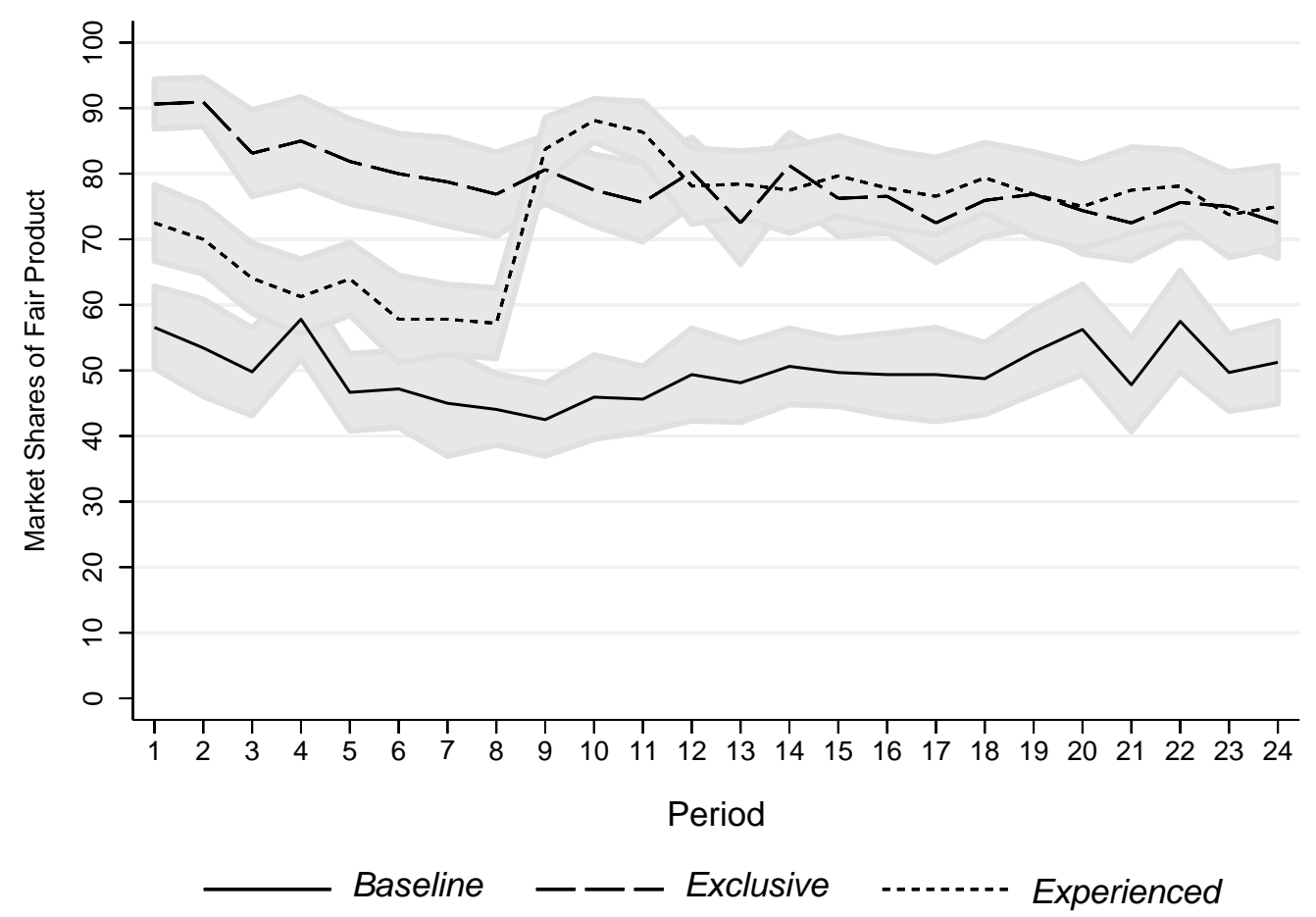

Notes: The figure shows completed transactions and ignores the cases in which a consumer did not purchase a product. Shaded areas represent standard errors of the mean.

The regression models in Table 6 corroborate the above findings and allow a more precise test of Hypothesis 4 that controls for differences in Part I behavior. The dependent variable is the choice of the fair product. Both models report coefficient estimates of random-effects GLS regressions. ${ }^{22}$ The binary treatment variables Exclusive (Charity) and Experienced (Charity) take on values of 1 in the corresponding conditions, while Baseline (Charity) is the omitted category.

Model 1 identifies the difference in social responsibility between Part I and Part II in each treatment, with Part I the omitted category. The large and positive coefficient for Exclusive (Charity) indicates that, relative to Baseline (Charity), socially responsible behavior is higher in Part I, following public discourse. The marginally significant coefficient for Experienced (Charity) captures the slightly higher frequency of fair products exchanged in Part I in this condition, relative to the Baseline (Charity). More importantly, the large and highly statistically significant

\footnotetext{
${ }^{22}$ The coefficient estimates of random-effects Probit regressions are reported in Table C.1 in Appendix C.
} 
coefficient for Part II $\times$ Experienced (Charity) indicates that, following public discourse, the frequency of socially responsible behavior increases substantially, even when participants have previous market experience. Model 2 additionally allows for a time trend in each condition. Exclusive (Charity) and Part II $\times$ Experienced (Charity) retain their large, positive and statistically significant coefficients.

Table 6: GLS (random-effects) regression of fair consumer product choice

\begin{tabular}{lcc}
\hline \hline & $(1)$ & $(2)$ \\
\hline Exclusive (Charity) & $0.326^{* * *}$ & $0.362^{* * *}$ \\
Experienced (Charity) & $(0.073)$ & $(0.073)$ \\
& $0.126^{*}$ & $0.176^{* * *}$ \\
Part II & $(0.064)$ & $(0.063)$ \\
& -0.004 & $-0.038^{* *}$ \\
Part II $\times$ Exclusive (Charity) & $(0.025)$ & $(0.017)$ \\
& $-0.071^{*}$ & -0.025 \\
Part II $\times$ Experienced (Charity) & $(0.039)$ & $(0.037)$ \\
& $0.159^{* * *}$ & $0.291^{* * *}$ \\
Period & $(0.055)$ & $(0.053)$ \\
& & 0.003 \\
Period $\times$ Exclusive (Charity) & & $(0.002)$ \\
Period $\times$ Experienced (Charity) & & $-0.008^{* * *}$ \\
Constant & & $(0.002)$ \\
& & $-0.011^{* * *}$ \\
\hline Observations & & $(0.003)$ \\
Number of subjects & & $0.497^{* * *}$ \\
\hline Test: Exclusive (Charity) $=$ & $(0.051)$ & $(0.052)$ \\
Part II $\times$ X Experienced (Charity) & 5,619 & 240 \\
\hline \hline
\end{tabular}

Notes: The dependent variable in all models takes on value 1 if a buyer purchased a fair product and 0 if the buyer purchased a harmful product. We omit the cases in which the consumer purchased no product. Baseline and Part I serve as omitted categories. Exclusive (Charity) and Experienced (Charity) are binary variables taking on value 1 in the corresponding condition and 0 otherwise. Part II is a binary variable taking on value 1 for data from period 9 to 24 and 0 otherwise. Period takes on integer values between 1 and 24. Standard errors (in parentheses) are clustered at the market level. The final row reports the p-value from a Wald test of the equality of the two coefficients. * significant at $10 \%$, ** significant at $5 \%$, ${ }^{* * *}$ significant at $1 \%$.

Turning to Hypothesis 4, the final row in the table provides the p-value from a Wald test of the equality of the two key treatment coefficients: Exclusive (Charity) and Part II $\times$ Experienced 
(Charity). In both models, we fail to reject at conventional significance levels that the treatment effects are equivalent. Therefore, while directionally the results suggest that the impact of public discourse is slightly lower for experienced market participants, this can be at least partly attributed to idiosyncratic differences in Part I behavior.

Result 4: While the effect of public discourse is smaller for experienced than inexperienced participants, this difference is not statistically significant.

Overall, Table 6 confirms the most important observation from Study 2: both public discourse interventions have large and positive effects on socially responsible market behavior; the treatment effects are statistically significant at the $p<0.01$ level. These findings qualitatively replicate the results from Study 1, in which all discourse conditions also had large and positive effects. $^{23}$

Figure 4: Effect of Public Discourse on Social Norms in Study 2

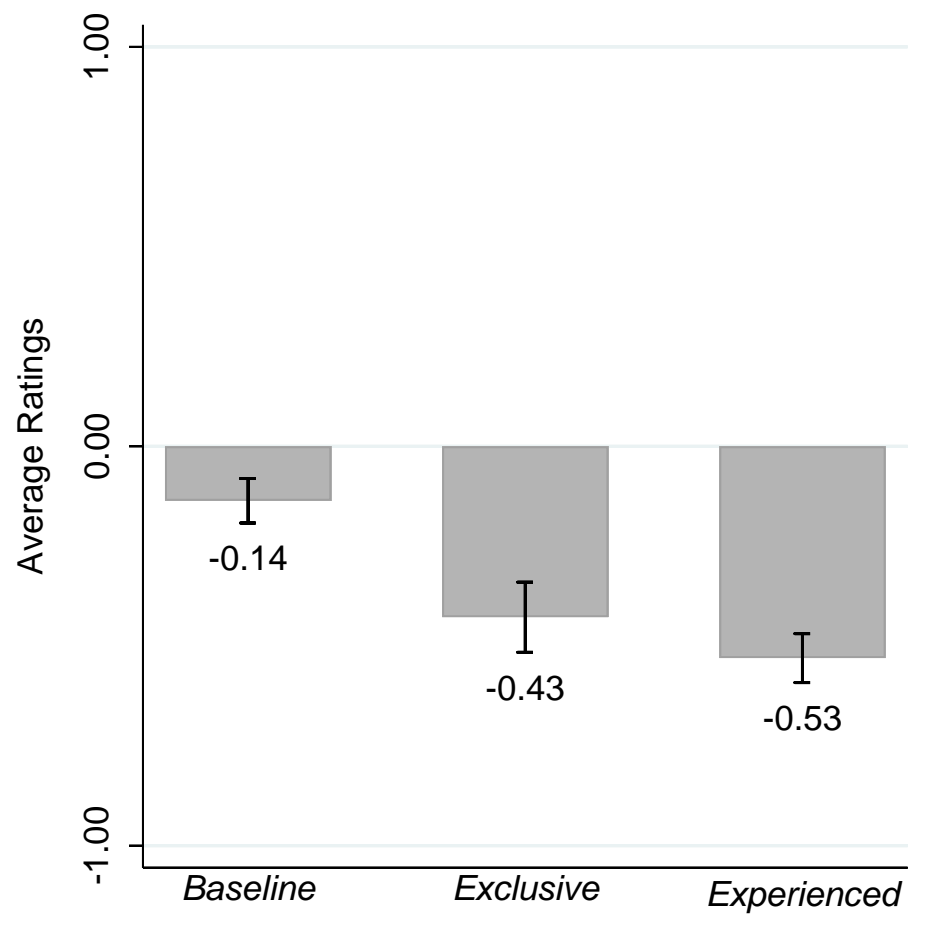

Notes. The figure shows the average rating of the appropriateness of exchanging the harmful product. The bars show the standard error of the mean at the market level.

\footnotetext{
${ }^{23}$ As in Study 1, fair products trade at higher prices, on average, than harmful products. The fair product trades, on average, at a price of 32, 34 and 34 in Baseline (Charity), Exclusive (Charity) and Experienced (Charity), respectively. The respective average prices of the harmful product are 22, 23 and 23.
} 
Finally, we also again observe an effect of the public discourse on social norms. Figure 4 presents the mean ratings of the social appropriateness of exchanging the harmful product, elicited at the end of the experiment. In the Baseline (Charity) condition, exchanging the harmful product is perceived to be slightly socially inappropriate, but in both conditions with public discourse, such behavior is perceived to be substantially more socially inappropriate. A regression of the kind in Table 4 using data from Study 2 shows that both treatment effects on perceptions of social appropriateness are highly statistically significant. ${ }^{24}$

\section{Content of the Public Discourse}

In this section, we analyze the content of the public discourse from both studies. The vast majority of subjects actively participated in the discourse by sending at least one message-98 and 95 percent of the subjects in Switzerland in Studies 1 and 2, respectively, and 98 percent of the subjects in China. On average, subjects made 6 and 4 statements in Switzerland in Studies 1 and 2, respectively, and 11 statements in China.

To classify the content of the debate, we recruited additional subjects to work as coders. These subjects had not participated in the earlier studies and were unaware of our research design or the treatment variation. We provided coders with a general description of the market experiment that was similar to the instructions in the experiment. The coders' task was to classify the content of the messages into categories. Our focus is on the following five categories: Recommending No impact on third parties (i.e., on passive participants in Study 1 or on the donation to the charity in Study 2), recommending Impact on third parties, Fairness, Efficiency and Self-interest. For example, recommending No impact refers to any statement supporting the exchange of the fair product or a boycott of the harmful one. Recommending Impact involves statements of support for the harmful product. Fairness corresponds to any statement appealing to fairness, the "right thing to do,” morality or demonstrating empathy for third parties. Efficiency and Self-interest similarly require appeals to such motivations. Coders saw the complete transcript for discourse in a market and rated each independent statement as belonging to one or more categories. The coders could classify each message into more than one category. Each market's discourse was evaluated by four

\footnotetext{
${ }^{24}$ Specifically, the estimated regression coefficients (standard errors) for Exclusive (Charity) and Experienced (Charity) are both negative and statistically significant at $\mathrm{p}<0.01$ (see Table C.2 in Appendix C).
} 
different coders. ${ }^{25}$ In our analysis, we consider a statement as belonging to a category if at least 3 of the 4 coders assigned it to that category.

Table 7: Fraction of subjects sending at least one message belonging to a category

\begin{tabular}{|c|c|c|c|c|c|c|c|c|}
\hline & \multicolumn{6}{|c|}{ Study 1} & \multicolumn{2}{|c|}{ Study 2 (Switz.) } \\
\hline & \multicolumn{2}{|c|}{ Veil } & \multicolumn{2}{|c|}{ No Veil } & \multicolumn{2}{|c|}{ Exclusive } & \multirow{2}{*}{$\begin{array}{l}\text { Exclusive } \\
\text { (Charity) }\end{array}$} & \multirow{2}{*}{$\begin{array}{c}\text { Experienced } \\
\text { (Charity) }\end{array}$} \\
\hline & Switz. & China & Switz. & China & Switz. & China & & \\
\hline No impact & 0.59 & 0.39 & 0.67 & 0.35 & 0.69 & 0.27 & 0.54 & 0.56 \\
\hline Impact & 0.09 & 0.09 & 0.03 & 0.09 & 0.11 & 0.22 & 0.12 & 0.14 \\
\hline Fairness & 0.51 & 0.43 & 0.58 & 0.47 & 0.65 & 0.29 & 0.31 & 0.39 \\
\hline Efficiency & 0.14 & 0.14 & 0.27 & 0.14 & 0.20 & 0.09 & 0.17 & 0.24 \\
\hline Self-interest & 0.10 & 0.14 & 0.06 & 0.21 & 0.18 & 0.30 & 0.08 & 0.10 \\
\hline
\end{tabular}

Notes. The table reports coding requiring that at least three of the four coders agree. "Switz." is short for Switzerland.

Table 7 shows the fraction of subjects that sent at least one message belonging to a category, separately for each study and condition and separately for Switzerland and China. ${ }^{26}$ For example, the top left cell in the table shows that 59 percent of subjects recommended not exchanging the harmful product (No impact) in condition Veil in Switzerland, while the cell immediately below shows that only nine percent argued for imposing negative externalities (Impact). The table shows that it is generally the case that a larger fraction of subjects argues for avoiding negative social impact (No impact) rather than for imposing the externality (Impact), a pattern that holds in each of the 8 different cases, i.e. in all conditions in both studies and locations. The table further shows that appeals to Fairness are typically much more frequent than either Efficiency or Self-interest; a pattern observed in all but one of the 16 possible comparisons. The one exception is in the Exclusive condition in China, where appeals to Self-interest are made by slightly more subjects than statements in support of Fairness. We also observe that arguments relating to Self-interest are made more often in China than in Switzerland in all three conditions in Study 1.

\footnotetext{
${ }^{25}$ We organized three sessions with 32 coders each. Each coder classified the discourse transcript in four markets. We provided the coders with a detailed description of each category. Besides a residual category, No category/Unclear, we also gave the coders the following additional categories: Agreement, Questions about what to do in the market game, General discussion of the game or the experiment, and Discussion of prices. Each statement had to belong to at least one category. The specific category descriptions provided to the coders are in Table D.1 in Appendix D for Study 1 and Table E.1 in Appendix E for Study 2. Tables D.2 and E.2 show the fraction of messages that are assigned to each category in Study 1 and 2, respectively. Tables D.3 and E.3 show the fraction of markets in which at least one message belongs to a specific category for Study 1 and 2, respectively.

${ }^{26}$ For the Exclusive condition, we consider only the statements made by buyers and sellers. Even though third parties also engaged in discourse, separately, these messages are irrelevant for shaping market behavior.
} 
In the following, we study the extent to which buyers' market behavior is (i) related to own statements made during public discourse and (ii) affected by the statements made by other market participants. Table 8 reports coefficient estimates from OLS regressions in which the dependent variable is the proportion of fair products bought. The unit of observation is a buyer. Each cell in the table shows the coefficient from a separate regression in which the corresponding category is the only explanatory variable. Columns (1) to (3) show the coefficient estimates for binary explanatory variables taking on the value of 1 if a buyer sent at least one message belonging to a given category and zero otherwise. We use that same compact way of reporting regression coefficients in columns (4) to (6), where the explanatory variables capture the fraction of other participants in the public discourse who sent at least one message belonging to a given category. ${ }^{27}$ Columns (1) and (4) show the results for Study 1 in Switzerland, columns (2) and (5) for Study 1 in China and columns (3) and (6) for Study 2. ${ }^{28}$ We pool the data from the three discourse conditions in Study 1 (Veil, No Veil, Exclusive) and from the two discourse conditions in Study 2 (Exclusive (Charity), Part II of Experienced (Charity)) in the respective regressions.

The signs of the coefficients reported in columns (1) to (3) show that the buyers' own contributions to the public debate are related to their purchasing behavior in sensible ways. For instance, we expect arguing for No impact to be positively associated with purchasing fair products, while arguing for Impact to have a negative association. In Switzerland in Study 1, we find that the associations between statements made in the public debate and behavior in the market are weak. In column (1), only the coefficient for Fairness is marginally statistically significant. A possible reason for the weak associations is the high market shares of the fair product in all three discourse conditions, which leaves relatively little variation to be explained. For example, in condition Veil in Switzerland in Study 1, 73 percent of all buyers never purchased the unfair product. In Study 1 in China, in contrast, all five coefficients shown in column (2) are at least marginally statistically significant. The association between contributions to the public debate and market behavior is particularly strong and highly significant for No impact, Fairness and

\footnotetext{
${ }^{27}$ In Veil and No Veil, other participants are the four other buyers, six sellers and five third parties. In Exclusive, Exclusive (Charity) and Experienced (Charity) other participants are the four other buyers and six sellers.

${ }^{28}$ We report all regressions in more detail in Tables D.4 through D.7 in Appendix D for Study 1 and Tables E.4 and E.5 in Appendix E for Study 2. We also report analogous regression analyses for sellers (see Tables D.8 through D.11 for Study 1 and Tables E.6 and E.7 for Study 2); these results are qualitatively similar.
} 
Efficiency. The coefficients for Switzerland in Study 2, shown in column (3), reveal that the association is particularly strong and highly significant for No impact, Impact and Self-interest.

Table 8: OLS regression coefficients of the fraction of fair products purchased by a buyer

\begin{tabular}{|c|c|c|c|c|c|c|}
\hline & \multicolumn{3}{|c|}{ Buyer's own statements } & \multicolumn{3}{|c|}{ Other's statements } \\
\hline & \multicolumn{2}{|c|}{ Study 1} & \multirow{2}{*}{$\begin{array}{c}\text { Study } 2 \\
\text { (3) }\end{array}$} & \multicolumn{2}{|c|}{ Study 1} & \multirow{2}{*}{$\begin{array}{c}\text { Study } 2 \\
\text { (6) }\end{array}$} \\
\hline & $\begin{array}{c}\text { Switzerland } \\
\text { (1) }\end{array}$ & $\begin{array}{c}\text { China } \\
(2)\end{array}$ & & $\begin{array}{c}\text { Switzerland } \\
(4)\end{array}$ & $\begin{array}{c}\text { China } \\
\text { (5) }\end{array}$ & \\
\hline No impact & $\begin{array}{c}0.048 \\
(0.033)\end{array}$ & $\begin{array}{c}0.179 * * * \\
(0.063)\end{array}$ & $\begin{array}{c}0.215^{* * * *} \\
(0.042)\end{array}$ & $\begin{array}{l}-0.090 \\
(0.081)\end{array}$ & $\begin{array}{c}0.189 \\
(0.155)\end{array}$ & $\begin{array}{c}0.251 * * * \\
(0.121)\end{array}$ \\
\hline Impact & $\begin{array}{c}-0.041 \\
(0.066)\end{array}$ & $\begin{array}{l}-0.130^{*} \\
(0.071)\end{array}$ & $\begin{array}{c}-0.294^{* * * *} \\
(0.062)\end{array}$ & $\begin{array}{c}0.008 \\
(0.151)\end{array}$ & $\begin{array}{c}-0.242 \\
(0.268)\end{array}$ & $\begin{array}{c}-0.904^{* * *} \\
(0.168)\end{array}$ \\
\hline Fairness & $\begin{array}{l}0.068^{*} \\
(0.037)\end{array}$ & $\begin{array}{c}0.207^{* * *} \\
(0.052)\end{array}$ & $\begin{array}{c}0.056 \\
(0.057)\end{array}$ & $\begin{array}{l}-0.006 \\
(0.080)\end{array}$ & $\begin{array}{c}0.302 \\
(0.186)\end{array}$ & $\begin{array}{c}-0.052 \\
(0.183)\end{array}$ \\
\hline Efficiency & $\begin{array}{c}0.049 \\
(0.036)\end{array}$ & $\begin{array}{c}0.219 * * * \\
(0.077)\end{array}$ & $\begin{array}{c}0.079 \\
(0.056)\end{array}$ & $\begin{array}{c}0.018 \\
(0.066)\end{array}$ & $\begin{array}{c}-0.171 \\
(0.394)\end{array}$ & $\begin{array}{c}0.170 \\
(0.211)\end{array}$ \\
\hline Self-interest & $\begin{array}{l}-0.096 \\
(0.068)\end{array}$ & $\begin{array}{c}-0.141^{*} \\
(0.076)\end{array}$ & $\begin{array}{c}-0.245 * * * \\
(0.077)\end{array}$ & $\begin{array}{c}0.089 \\
(0.180)\end{array}$ & $\begin{array}{c}-0.404^{*} \\
(0.207)\end{array}$ & $\begin{array}{c}-0.907 * * \\
(0.401)\end{array}$ \\
\hline Observations & 120 & 120 & 160 & 120 & 120 & 160 \\
\hline
\end{tabular}

Notes. The columns report the coefficients of regressions of the proportion of the fair product purchased by a buyer on whether the buyer made a particular statement (columns 1 to 3 ) and on the fraction of other participants who made that statement in the public debate (columns 4 to 6 ). We pool the data for all discourse conditions in a given country and study. For Study 2, we include only purchasing behavior from Part II. The columns show the coefficients for each category in models that regress the fraction of the fair product on each of the categories separately. That is, each coefficient corresponds to a separate regression with only one explanatory variable. We omit the cases in which a buyer purchased no product. Standard errors (in parentheses) are clustered at the market level, ${ }^{* * *} \mathrm{p}<0.01,{ }^{* *} \mathrm{p}<0.05,{ }^{*} \mathrm{p}<0.1$.

The coefficients reported in columns (4) to (6) suggest some influence of others statements on buyers' purchasing behavior. In all cases where a coefficient is at least marginally significant, it has the expected sign. Overall, however, the associations are weaker compared to the models shown in columns (1) to (3). In Switzerland in Study 1, were we have relatively little variation in buyers' purchasing behavior, none of the coefficients is statistically significant. For China, only the coefficient for Self-interest is marginally significant. We find that buyers are most strongly influenced by other market participants' statements in Study 2. All five coefficients have the expected sign, and the coefficients for No impact and Impact are highly significant, while the coefficient on Self-interest is significant at the five percent level.

Despite the intuitive associations that we regularly observe in Table 8, we interpret these findings only very cautiously. We have no reason to claim that these relationships are causal- 
e.g., it is very likely that consumers inclined to buy the fair product are more likely to make statements supporting such behavior. Moreover, this portion of our analysis is highly exploratory and should be taken with caution due to the likely presence of noise in coding and interpreting the statements. Nevertheless, it is reassuring that the analysis of the transcripts provides some indication that the messages sent during discourse are reflective of participants' subsequent market behavior.

\section{Conclusions}

We investigate the extent to which public discourse-whereby individuals can engage in communication and discuss what constitutes appropriate behavior-influences socially responsible market behavior and the norms governing such conduct. Our main finding is quite striking: all of our conditions that introduce public discourse produce substantially higher degrees of market social responsibility, relative to a control condition in which discourse is absent. Across eight such comparisons - six in Study 1 and two in Study 2-and in two populations, one from Switzerland and one from China, that vary in their pre-existing degrees of market social responsibility, we always find the positive effects of public discourse to be large in magnitude and statistically significant. This is particularly surprising, since we designed many of our conditions to introduce features we thought would likely eliminate the positive impacts of public discourse, or possibly even yield negative effects on socially responsible conduct. Thus, our study provides consistent evidence that deliberation can lead groups of anonymous individuals to change their market behavior in a way that reduces negative external effects and yields greater aggregate welfare.

We also find that public discourse impacts social norms regarding appropriate market behavior. Combined with the persistent positive impacts across rounds in our experiment-from a single early experience engaging in public discourse-this suggests that the benefits of discourse are not transitory.

While our results echo similar positive impacts of communication in other settings, such as social dilemmas, our findings provide an important novel direction for such research. Unlike earlier work, our study finds large positive impacts of communication in a setting in which those communicating ultimately end up worse off in terms of material outcomes as a result of the actions that they agree to take in the public discourse. Aside from demonstrating a new way in which 
communication can improve efficiency, this finding is of crucial importance for our motivating research question. Public campaigns and discourse can mitigate harmful external impacts of market activity only by stimulating voluntary change towards more costly production technologies. Thus, the finding that it is possible for collections of anonymous individuals to reach such agreements that then shape their market behavior is important. However, whether such positive impacts extend to market settings comprising tens or hundreds of thousands of consumers remains an open question.

Indeed, our work also requires additional important caveats. While we investigate many treatment comparisons that vary the nature of public discourse, there are of course many additional potentially important factors that we omit. This includes important sources of heterogeneity among market actors, such as nationality, ethnicity and income, which may make it difficult to obtain agreements. Furthermore, the specific nature of technology and discourse can vary in many ways that extend far beyond the simple kind of discussions in our study. Nevertheless, our design can be easily extended to incorporate heterogeneity and other forms of discourse in order to investigate the importance of these factors.

Additionally, the degree to which laboratory findings generalize to non-laboratory settings is an important concern with all laboratory experiments. Our study is motivated by the observation of large public discourse campaigns around the World intended to promote more responsible market conduct. Whether such campaigns are effective is an open question that is challenging to address with non-laboratory data, where it is impossible to observe counterfactuals or exogenously manipulate the presence and nature of such discourse. Our laboratory evidence provides an indication that the kind of discourse encouraged by such campaigns can facilitate socially responsible market behavior. We make no claims that it will always, or even necessarily frequently, do so. Nevertheless, the robustness of our main finding to our attempts to introduce additional features, motivated by observations outside the laboratory, to reduce the positive impact of public discourse suggest that the positive impacts we observe may be grounded on a strong behavioral foundation. Thus, while our results provide compelling evidence that public discourse can enhance market social responsibility, one of our key contributions is to provide a starting point from which other inquiries into the precise ways in which such discourse is effective can be investigated. 


\section{References}

Andreoni, J., and Rao, J. M. (2011). The Power of Asking: How Communication Affects Selfishness, Empathy, and Altruism. Journal of Public Economics, 95(7-8), 513-520.

Agranov, M. and Tergiman, C. (2014). Communication in Multilateral Bargaining. Journal of Public Economics, 118, 75-85.

Bartling, B., Valero, V., and Weber, R. (2019). On the Scope of Externalities in Experimental Markets. Experimental Economics, 22 (3), 610-624.

Bartling, B., Valero, V., and Weber, R. (2020). The Causal Effect of Income Growth on Consumer Social Responsibility. SSRN Discussion Paper No. 3249788.

Bartling, B., Weber, R. A., and Yao, L. (2015). Do Markets Erode Social Responsibility? Quarterly Journal of Economics, 130(1), 219-266.

Bénabou, R., Falk, A., and Tirole, J. (2019). Narratives, Imperatives, and Moral Persuasion. NBER working paper.

Bénabou, R., and Tirole, J. (2010). Individual and Corporate Social Responsibility. Economica, 77(305), 1-19.

Blume, A., and Ortmann, A. (2007). The Effects of Costless Pre-play Communication: Experimental Evidence from Games with Pareto-ranked Equilibria. Journal of Economic Theory, 132(1), 274-290.

Bochet, O., Page, T., and Putterman, L. (2006). Communication and Punishment in Voluntary Contribution Experiments. Journal of Economic Behavior and Organization, 60(1), 11-26.

Brandts, J., and Cooper, D. J. (2007). It's what you say, not what you pay: an experimental study of manager employee relationships in overcoming coordination failure. Journal of European Economic Association, 5 (6):1223-1268.

Charness, G., and Dufwenberg, M. (2006). Promises and Partnership. Econometrica, 74(6), 15791601.

Cooper, R., DeJong, D. V., Forsythe, R., and Ross, T. W. (1992). Communication in Coordination Games. Quarterly Journal of Economics, 107(2), 739-771.

Danz, D., Engelmann, D., and Kübler, D. (2020). Do Legal Standards Affect Ethical Concerns of Consumers? CRC TRR 190 Discussion Paper No. 234. 
Dawes, R. M., McTavish, J., and Shaklee, H. (1977). Behavior, Communication, and Assumptions about other People's Behavior in a Commons Dilemma Situation. Journal of Personality and Social Psychology, 35(1), 1.

Dufwenberg, M., Heidhues, P., Kirchsteiger, G., Riedel, F., and Sobel, J. (2011). Other-regarding Preferences in General Equilibrium. Review of Economic Studies, 78(2), 613-639.

Ellman, M., and Pezanis-Christou, P. (2010). Organizational Structure, Dommunication, and Group Ethics. American Economic Review, 100(5), 2478-91.

Engelmann, D., Friedrichsen, J., and Kübler, D. (2018). Fairness in Markets and Market experiments (No. SP II 2018-203). WZB Discussion Paper.

Exley, C. L. (2020). Using Charity Performance Metrics as an Excuse Not to Give. Management Science, 66(2), 553-563.

Hainmueller, J., Hiscox, M. J., and Sequeira, S. (2015). Consumer Demand for Fair Trade: Evidence from a Multistore Field Experiment. Review of Economics and Statistics, 97(2), 242-256.

Irlenbusch, B., and Saxler, D. (2019). The Role of Social Information, Market Framing, and Diffusion of Responsibility as Determinants of Socially Responsible Behavior. Journal of Behavioral and Experimental Economics, 80, 141-161.

Isaac, R. M., \& Walker, J. M. (1988). Communication and free-riding behavior: The voluntary contribution mechanism. Economic Inquiry, 26(4), 585-608.

Kessler, J. B., and Leider, S. (2012). Norms and Contracting. Management Science, 58(1), 62-77.

Kirchler, M., Huber, J., Stefan, M., and Sutter, M. (2015). Market Design and Moral Behavior. Management Science, 62(9), 2615-2625.

Kriss, P. H., Blume, A., and Weber, R. A. (2016). Coordination with Decentralized Costly Communication. Journal of Economic Behavior and Organization, 130, 225-241.

Krupka, E. L., Leider, S., and Jiang, M. (2016). A Meeting of the Minds: Informal Agreements and Social Norms. Management Science, 63(6), 1708-1729.

Krupka, E., \& Weber, R. A. (2009). The focusing and informational effects of norms on pro-social behavior. Journal of Economic Psychology, 30(3), 307-320.

Ockenfels, A., Werner, P., and Edenhofer, O. (2020). Pricing Externalities and Moral Behaviour. Nature Sustainability, https://doi.org/10.1038/s41893-020-0554-1. 
Ostrom, E., Walker, J., and Gardner, R. (1992). Covenants with and without a sword: Selfgovernance is possible. American Political Science Review, 86(2), 404-417.

Pigors, M., and Rockenbach, B. (2016). Consumer Social Responsibility. Management Science, 62(11), 3123-3137.

Rode, J., Le Menestrel, M., and Hogarth, R. (2008), Ethical Differentiation and Market Behaviour: An experimental approach. Journal of Economic Behavior and Organization, 66, 265-280.

Sutter, M., Huber, J., Kirchler, M., Stefan, M., and Walzl, M. (2020). Where to Look for the Morals in Markets? Experimental Economics, 23, 30-52. 


\section{Supplemental Appendix}

\section{A. Study 1: Additional Figures and Tables}

Figure A.1: Market shares of fair products over periods by treatment and country

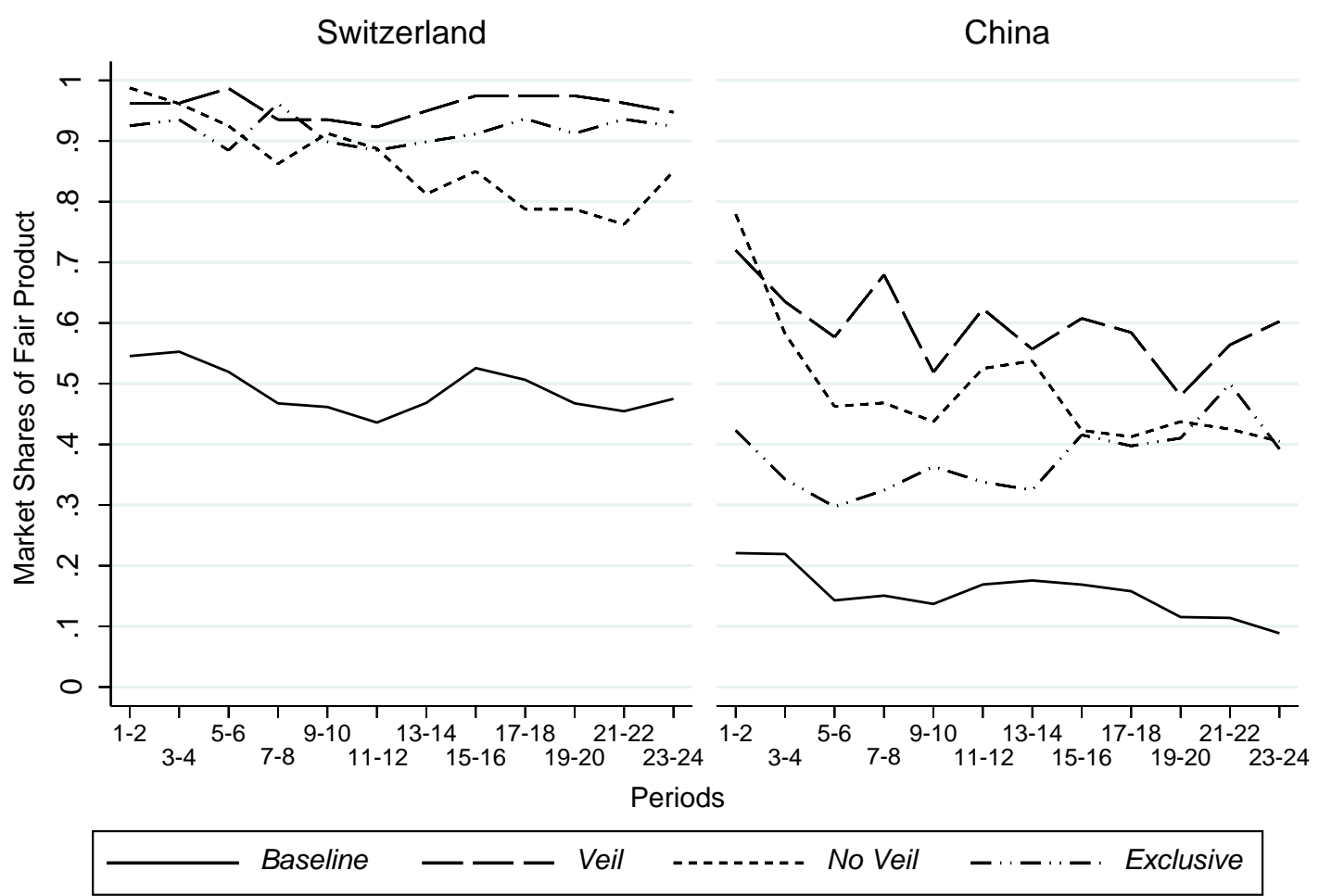

Notes. The figure shows completed transactions and ignores the cases in which a consumer did not purchase a product. Data are aggregated in blocks of two periods to smooth random variation across periods. 
Figure A.2: CDFs of market shares of fair products by treatment and country

Switzerland

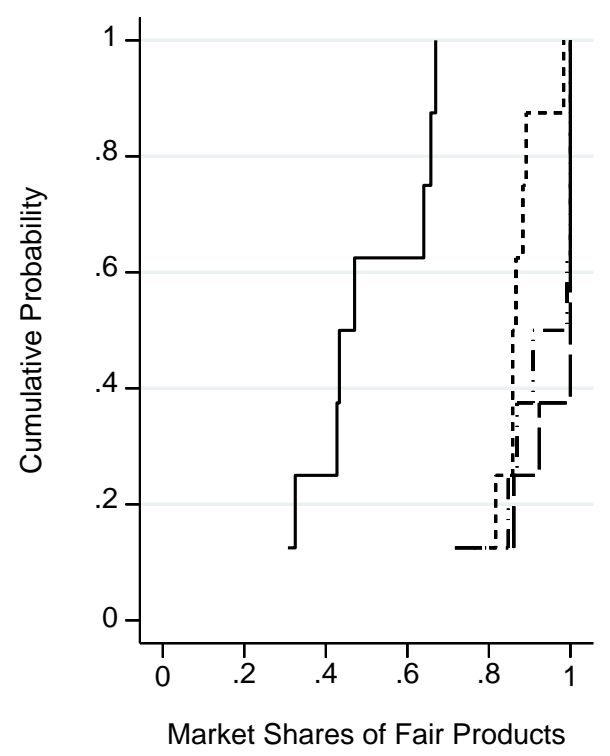

China

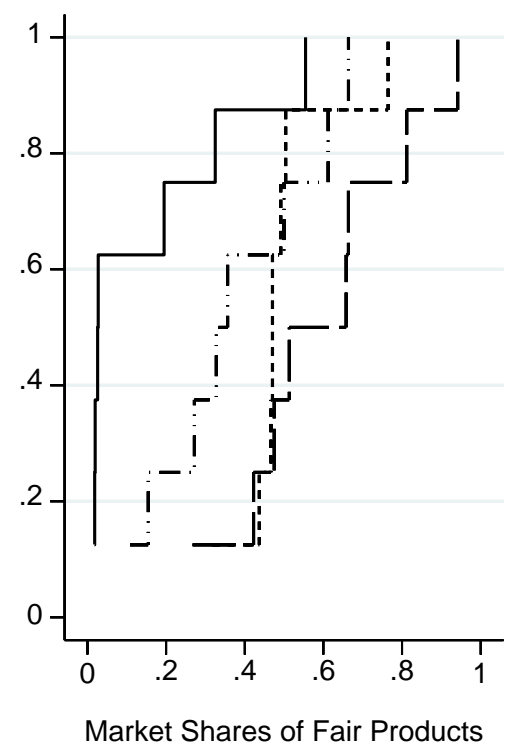

Baseline - - Veil

No Veil

$-\cdots-\cdots-$ Exclusive

Notes. The figure shows completed transactions and ignores the cases in which a consumer did not purchase a product. We conducted eight markets per treatment, which serve as units of observation in the figure.

Table A.1: Wilcoxon rank-sum tests at the market (consumer) level, two-sided

\begin{tabular}{lcccc}
\hline \multicolumn{1}{c}{$p$-values } & Baseline & Veil & No Veil & Exclusive \\
\hline \multirow{2}{*}{ Baseline } & - & 0.005 & 0.012 & 0.027 \\
\multirow{2}{*}{ Veil } & 0.001 & $(0.000)$ & $(0.000)$ & $(0.000)$ \\
\multirow{2}{*}{ No Veil } & $(0.000)$ & - & 0.248 & 0.093 \\
& 0.001 & 0.014 & $(0.145)$ & $(0.008)$ \\
Exclusive & $(0.000)$ & $(0.001)$ & - & 0.293 \\
& 0.001 & 0.340 & 0.140 & $(0.055)$ \\
\hline
\end{tabular}

Notes. The p-values in the lower triangle correspond to Switzerland, the p-values in the upper, shaded area correspond to China. 
Table A.2: Random-effects probit regressions of fair consumer product choice

\begin{tabular}{|c|c|c|c|c|c|c|}
\hline & \multicolumn{3}{|c|}{ Switzerland } & \multicolumn{3}{|c|}{ China } \\
\hline & (1) & (2) & (3) & (4) & (5) & (6) \\
\hline \multirow[t]{2}{*}{ Veil } & $3.368 * * *$ & $3.171^{* * *}$ & & $1.966 * * *$ & $1.798 * * *$ & \\
\hline & $(0.516)$ & $(0.550)$ & & (0.392) & (0.359) & \\
\hline \multirow[t]{2}{*}{ No Veil } & $1.827 * * *$ & $2.538 * * *$ & & $1.571^{* * *}$ & $1.603^{* * *}$ & \\
\hline & $(0.364)$ & $(0.514)$ & & $(0.336)$ & (0.330) & \\
\hline \multirow[t]{2}{*}{ Exclusive } & $2.635 * * *$ & $2.399 * * *$ & & $1.149 * * *$ & 0.591 & \\
\hline & $(0.530)$ & $(0.570)$ & & (0.373) & $(0.418)$ & \\
\hline \multirow[t]{2}{*}{ Discourse } & & & $2.817 * * *$ & & & $1.374 * * *$ \\
\hline & & & $(0.418)$ & & & $(0.326)$ \\
\hline \multirow[t]{2}{*}{ Period } & & $-0.013 *$ & $-0.013 *$ & & $-0.033 * *$ & $-0.033 * *$ \\
\hline & & $(0.007)$ & $(0.007)$ & & $(0.013)$ & $(0.013)$ \\
\hline \multirow[t]{2}{*}{ Period $\times$ Veil } & & 0.018 & & & 0.016 & \\
\hline & & $(0.019)$ & & & $(0.018)$ & \\
\hline \multirow{2}{*}{ Period $\times$ No Veil } & & $-0.049 * * *$ & & & 0.000 & \\
\hline & & $(0.019)$ & & & (0.019) & \\
\hline \multirow[t]{2}{*}{ Period $\times$ Exclusive } & & 0.021 & & & $0.047 * * *$ & \\
\hline & & $(0.021)$ & & & $(0.017)$ & \\
\hline \multirow[t]{2}{*}{ Period $\times$ Discourse } & & & -0.016 & & & 0.019 \\
\hline & & & $(0.014)$ & & & $(0.011)$ \\
\hline \multirow[t]{2}{*}{ Constant } & 0.191 & $0.357^{*}$ & $0.371^{*}$ & $-1.560 * * *$ & $-1.190 * * *$ & $-1.201 * * *$ \\
\hline & $(0.149)$ & (0.189) & $(0.168)$ & $(0.316)$ & $(0.285)$ & $(0.285)$ \\
\hline Observations & 3770 & 3770 & 3770 & 3705 & 3705 & 3705 \\
\hline Subjects & 160 & 160 & 160 & 160 & 160 & 160 \\
\hline
\end{tabular}

Notes. The dependent variable in all models takes on value 1 if a buyer purchased a fair product and 0 if the buyer purchased a harmful product. We omit the cases in which consumers purchased no product. Baseline serves as omitted category. Period takes on integer values between 1 and 24 . Discourse takes on value 1 in Veil, No Veil and Exclusive, and 0 otherwise. The table reports raw probit coefficients. All standard errors (in parentheses) are clustered at the market level, ${ }^{* * *} \mathrm{p}<0.01$, ${ }^{* *} \mathrm{p}<0.05,{ }^{*} \mathrm{p}<0.1$. 
Table A.3: Tests of equality of coefficients from regressions of fair consumer product choice

\begin{tabular}{lccc}
\hline \hline \multicolumn{1}{c}{$p$-values } & Veil & No Veil & Exclusive \\
\hline Veil & - & 0.217 & 0.038 \\
No Veil & 0.009 & - & 0.203 \\
Exclusive & 0.448 & 0.186 & - \\
\hline
\end{tabular}

Notes. To test for equality of coefficients, we use the results of model (1) for Switzerland and model (4) for China of Table 3. The p-values in the shaded area correspond to China and the rest to Switzerland.

Table A.4: Random-effects probit regressions of fair consumer product choice

(1)

(2)

\begin{tabular}{lcc}
\hline Veil & $3.028^{* * *}$ & \\
No Veil & $(0.477)$ & \\
& $1.681^{* * *}$ & \\
Exclusive & $(0.303)$ & \\
& $2.370^{* * *}$ & \\
Discourse & $(0.432)$ & $2.297^{* * *}$ \\
& & $(0.297)$ \\
China & $-1.758^{* * *}$ & $-1.779^{* * *}$ \\
& $(0.447)$ & $(0.451)$ \\
China $\times$ Veil & -0.976 & \\
& $(0.683)$ & \\
China $\times$ No Veil & -0.039 & \\
& $(0.512)$ & \\
China $\times$ Exclusive & $-1.169^{*}$ & \\
China $\times$ Discourse & $(0.646)$ & -0.649 \\
& & $0.513)$ \\
Constant & & 0.139 \\
& 0.132 & $(0.224)$ \\
\hline Observations & $(0.222)$ & 3475 \\
Number of Subjects & 7475 & 320 \\
\hline \hline
\end{tabular}

Notes. Baseline in Switzerland serves as omitted category in this model. All standard errors (in parentheses) are clustered at the market level, ${ }^{* * *} \mathrm{p}<0.01,{ }^{* *} \mathrm{p}<0.05,{ }^{*} \mathrm{p}<0.1$. 
Table A.5: Ordered probit regressions of social appropriateness

\begin{tabular}{lcc}
\hline \hline & Switzerland & China \\
& $(1)$ & $(2)$ \\
\hline Veil & $-1.358^{* * *}$ & $-0.951^{* * *}$ \\
No Veil & $(0.228)$ & $(0.276)$ \\
& $-0.859^{* * *}$ & $-0.447^{* *}$ \\
Exclusive & $(0.158)$ & $(0.181)$ \\
& $-0.985^{* * *}$ & $-0.672^{* * *}$ \\
\hline Observations & $(0.226)$ & $(0.238)$ \\
\hline \hline Notes. The dependent variable in all models take values from -1 to 1. \\
Baseline serves as omitted category. All standard errors (in parentheses) \\
are clustered at the market level, ${ }^{* * *} \mathrm{p}<0.01,{ }^{* *} \mathrm{p}<0.05,{ }^{*} \mathrm{p}<0.1$.
\end{tabular}

Table A.6: Tests of equality of coefficients from regressions of social appropriateness

\begin{tabular}{lccc}
\hline \multicolumn{1}{c}{$p$-values } & Veil & No Veil & Exclusive \\
\hline Veil & - & 0.037 & 0.316 \\
No Veil & 0.057 & - & 0.236 \\
Exclusive & 0.265 & 0.618 & - \\
\hline
\end{tabular}

Notes. To test for equality of coefficients, we use the results of model (1) for Switzerland and model (2) for China of Table 4. The p-values in the shaded area correspond to China and the rest to Switzerland.

\section{B. Supplementary Condition: Reflection}

In this section, we report the results of an additional, post hoc, treatment added to Study 1 in order to investigate the extent to which the positive impact of public discourse on market social responsibility is due to discourse per se-i.e., the exchange of views and arguments between market participants—or due to prompting individuals to spend time thinking about appropriate market behavior, which does not necessarily involve discourse. In fact, earlier experiments that study the role of communication in strategic settings typically confound these two mechanisms.

To separate these two possible channels, we conducted condition Reflection. As in No Veil, subjects in Reflection first learn their roles in the market game. In contrast to No Veil, however, 
subjects do not have the opportunity to enter into a public discourse with others but can, instead, write their thoughts about what constitutes "appropriate” or "acceptable” market behavior privately into the computer interface. This way, subjects are encouraged to think about appropriate market behavior without being influenced by others. ${ }^{29}$

The Reflection condition also allows us to investigate a kind of prime often present in campaigns that are intended to foster socially responsible behavior by encouraging people to think about their behavior and the right thing to do. Does encouraging people to think about the appropriateness of their behavior change their market behavior?

Figure B.1 illustrates that encouraging people to think about the appropriateness of their market behavior fosters socially responsible behavior in our experimental markets, both in Switzerland and China. The market share of the fair product is 67 percent in Reflection in Switzerland, compared to 49 percent in Baseline. The same result prevails in China, where the market share of the fair product is 43 percent in Reflection, compared to 15 percent in Baseline. Wilcoxon rank-sum test at the market (consumer) levels indicate that these differences are statistically significant; $\mathrm{p}=0.036(\mathrm{p}=0.023)$ for Switzerland and $\mathrm{p}=0.016(\mathrm{p}=0.000)$ for China. ${ }^{30}$

Figure B.1 further illustrates the additional impact of discourse per se, i.e., the impact of discourse on top of making people think about appropriate market behavior, by comparing markets shares of the fair product in Reflection and No Veil. The effect of discourse in No Veil is about twice as large as the effect of private deliberation in Reflection in Switzerland. In China, in contrast, the effect of private deliberation is almost as large as the effect of discourse. Indeed, the difference between Reflection and No Veil is statistically significant only in Switzerland, p=0.002 ( $p=0.011)$, but not in China, $p=0.207(p=0.196)$. Overall, the data show that a sizable part of the effect of public discourse on socially responsible market behavior is driven by encouraging people to think about the appropriateness of their behavior, suggesting that public campaigns can also be effective when they prompt individuals to think about the consequences of their market activities. Indeed, many campaigns take this form.

\footnotetext{
${ }^{29}$ We collected data from 8 markets with 16 participants each in both countries; hence, 256 subjects participated in total in condition Reflection. We followed the same procedures as described in Section 3.1.4.

${ }^{30}$ The prices of the fair and harmful products in Reflection are comparable to all other conditions. The fair and harmful products trade, on average, at 26 and 20, respectively, in Switzerland and at 26 and 18, respectively, in China.
} 
Figure B.1: Public Discourse vs. Reflection

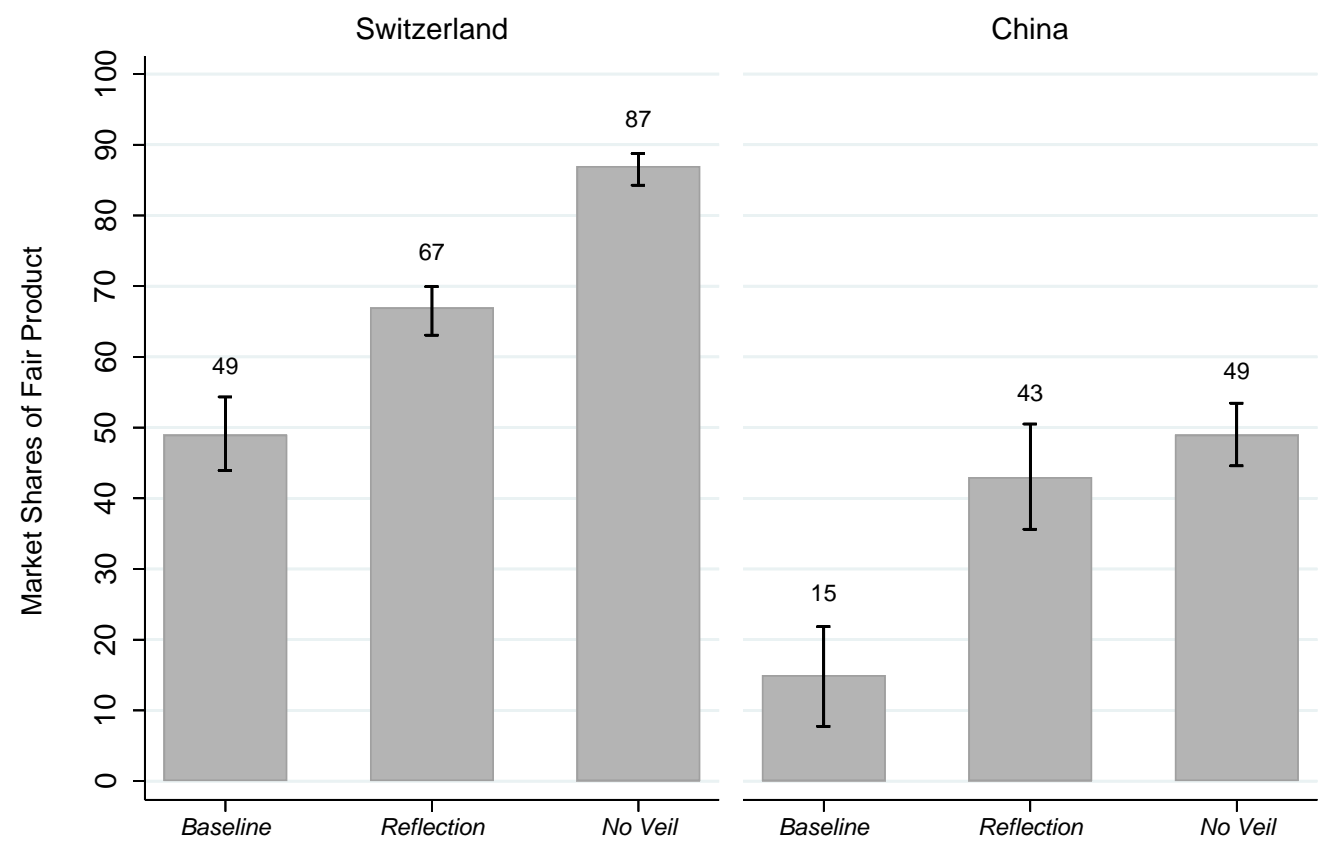

Notes: The figure shows completed transactions and ignores the cases in which a consumer did not purchase a product, thereby imposing no loss on third parties. The intervals correspond to the standard error of the mean at the market level.

The results from this section might be of broader interest, beyond our particular research question, in light of the large literature on communication in games. Experimental papers that study the effect of adding some form of communication among players to a game typically do not disentangle whether communication per se causes treatment differences or whether these differences are observed because the option to communicate prompts players to think about their behavior and provides them with time to do so. However, in many cases it can be of interest to better understand the underlying mechanisms that drive behavioral change. In our particular case, for example, it is valuable to know that a policy that encourages people to think about what constitutes "appropriate" market behavior can be effective, even without providing the opportunity to engage in a public discourse. 


\section{Study 2: Additional Tables}

Table C.1: Random-effects Probit regressions of fair consumer product choice

\begin{tabular}{lcc}
\hline \hline & $(1)$ & $(2)$ \\
\hline Exclusive (Charity) & $1.783^{* * *}$ & $2.061^{* * *}$ \\
Experienced (Charity) & $(0.464)$ & $(0.486)$ \\
& 0.433 & $0.721^{* *}$ \\
Part II & $(0.311)$ & $(0.316)$ \\
& -0.048 & $-0.246^{* * *}$ \\
Part II $\times$ Exclusive (Charity) & $(0.139)$ & $(0.017)$ \\
& $-0.491^{* *}$ & 0.185 \\
Part II $\times$ Experienced (Charity) & $(0.249)$ & $(0.257)$ \\
& $0.832^{* * *}$ & $1.609^{* * *}$ \\
Period & $(0.309)$ & $(0.334)$ \\
& & 0.016 \\
Period $\times$ Exclusive & & $(0.010)$ \\
Period $\times$ Experienced & & $-0.057^{* * *}$ \\
Constant & & $(0.014)$ \\
& & $-0.063^{* * *}$ \\
\hline Observations & & $(0.014)$ \\
Number of subjects & & 0.173 \\
\hline \hline Test: Exclusive $=$ Part II $\times$ Experienced & 0.241 & $(0.270)$ \\
\hline \hline
\end{tabular}

Notes: The dependent variable in all models takes on value 1 if a buyer purchased a fair product and 0 if the buyer purchased a harmful product. We omit the cases in which the consumer purchased no product. Baseline and Part I serve as omitted categories. Exclusive (Charity) and Experienced (Charity) are binary variables taking on value 1 in the corresponding condition and 0 otherwise. Part II is a binary variable taking on value 1 for data from period 9 to 24 and 0 otherwise. Period takes on integer values between 1 and 24. Standard errors (in parentheses) are clustered at the market level. The final row reports the p-value from a Wald test of the equality of the two coefficients. * significant at $10 \%, * *$ significant at $5 \%, * * *$ significant at $1 \%$. 
Table C.2: Regressions of social appropriateness

\begin{tabular}{lcc}
\hline \hline & OLS & Ordered Probit \\
\hline Exclusive (Charity) & $-0.292^{* * *}$ & $-0.686^{* * *}$ \\
Experienced (Charity) & $(0.102)$ & $(0.235)$ \\
& $-0.394^{* * *}$ & $-0.914^{* * *}$ \\
Constant & $(0.081)$ & $(0.190)$ \\
& $-0.136^{* *}$ & - \\
\hline Observations & $(0.055)$ & 528 \\
\hline \hline
\end{tabular}

Notes. The dependent variable in all models take values from -1 to 1 corresponding to the numerical scores previously described. Baseline serves as omitted category. All standard errors (in parentheses) are clustered at the market level, ${ }^{* * *} \mathrm{p}<0.01,{ }^{* *} \mathrm{p}<0.05,{ }^{*} \mathrm{p}<0.1$. 


\section{Content Analysis for Study 1}

Table D.1: Different coding categories and their description

\begin{tabular}{|c|c|}
\hline Category & Description \\
\hline $\begin{array}{l}\text { Recommending no } \\
\text { impact on Cs }\end{array}$ & $\begin{array}{l}\text { Any statement supporting the exchange of the "products with no } \\
\text { effect on Participant C", or the boycott of the "products with a loss } \\
\text { for Participant C," irrespective of whether or not a reason is given. } \\
\text { Note that the statements can be explicit or implicit. }\end{array}$ \\
\hline $\begin{array}{l}\text { Recommending } \\
\text { impact on Cs }\end{array}$ & $\begin{array}{l}\text { Any statement supporting the exchange of the "products with a loss } \\
\text { for Participant C,” irrespective of whether or not a reason is given. } \\
\text { Note that the statements can be explicit or implicit. }\end{array}$ \\
\hline $\begin{array}{l}\text { Discussion of } \\
\text { prices }\end{array}$ & $\begin{array}{l}\text { Any statement mentioning or discussing the prices of the products } \\
\text { exchanged. }\end{array}$ \\
\hline Fairness & $\begin{array}{l}\text { Any statement supporting an argument by appealing to fairness, the } \\
\text { "right thing to do" or morality, or demonstrating empathy for } \\
\text { Participants C. }\end{array}$ \\
\hline Efficiency & $\begin{array}{l}\text { Any statement supporting an argument by appealing to efficiency } \\
\text { (maximizing the total earnings of everybody), sustainability, or } \\
\text { comparing the cost of having no impact on Participants C with the } \\
\text { loss incurred by Participants C. }\end{array}$ \\
\hline Self-interest & $\begin{array}{l}\text { Any statement supporting an argument by appealing to selfishness, } \\
\text { maximization of own profit or earnings. }\end{array}$ \\
\hline Agreement & Any statement agreeing with or supporting a previous argument. \\
\hline $\begin{array}{l}\text { Questions about } \\
\text { what to do in the } \\
\text { market game }\end{array}$ & $\begin{array}{l}\text { Any statement questioning what participants should do in the } \\
\text { market game, in the form of a question or not. }\end{array}$ \\
\hline $\begin{array}{l}\text { General discussion } \\
\text { of the game or the } \\
\text { experiment }\end{array}$ & $\begin{array}{l}\text { Any statement that mentions or discusses the market game or the } \\
\text { experiment without clearly prescribing, supporting or justifying any } \\
\text { particular behavior. }\end{array}$ \\
\hline $\begin{array}{l}\text { No category/ } \\
\text { Unclear }\end{array}$ & $\begin{array}{l}\text { Any statement that does not fit in any category or for which the } \\
\text { meaning is unclear. Use this category for any messages that you } \\
\text { cannot otherwise categorize. You should not use this category if you } \\
\text { also assign another category to a message. }\end{array}$ \\
\hline
\end{tabular}


Table D.2: Fraction of messages assigned to each category

\begin{tabular}{lcccccc}
\hline & \multicolumn{2}{c}{ Veil } & \multicolumn{2}{c}{ No Veil } & \multicolumn{2}{c}{ Exclusive } \\
& Switz. & China & Switz. & China & Switz. & China \\
\hline No impact on Cs & 0.13 & 0.06 & 0.22 & 0.06 & 0.15 & 0.02 \\
Impact on Cs & 0.01 & 0.01 & 0.01 & 0.01 & 0.01 & 0.02 \\
Prices & 0.12 & 0.04 & 0.05 & 0.07 & 0.13 & 0.04 \\
Fairness & 0.11 & 0.06 & 0.18 & 0.07 & 0.16 & 0.03 \\
Efficiency & 0.02 & 0.02 & 0.07 & 0.01 & 0.04 & 0.01 \\
Self-interest & 0.02 & 0.02 & 0.02 & 0.03 & 0.03 & 0.03 \\
Agreement & 0.19 & 0.05 & 0.23 & 0.05 & 0.18 & 0.04 \\
Questions & 0.05 & 0.05 & 0.06 & 0.03 & 0.08 & 0.05 \\
General discussion & 0.15 & 0.22 & 0.14 & 0.22 & 0.20 & 0.23 \\
No category & 0.27 & 0.25 & 0.18 & 0.22 & 0.10 & 0.27 \\
\hline \hline
\end{tabular}

Notes. The table reports coding where at least three of the four coders agreed. Coders could assign a message to several categories.

Table D.3: Fraction of markets in which at least one message belongs to a category

\begin{tabular}{lcccccc}
\hline \hline & \multicolumn{2}{c}{ Veil } & \multicolumn{2}{c}{ No Veil } & \multicolumn{2}{c}{ Exclusive } \\
& Switz. & China & Switz. & China & Switz. & China \\
\hline No impact on Cs & 1 & 1 & 1 & 1 & 1 & 0.875 \\
Impact on Cs & 0.500 & 0.625 & 0.375 & 0.500 & 0.625 & 1 \\
Prices & 1 & 1 & 0.875 & 0.750 & 1 & 0.875 \\
Fairness & 1 & 1 & 1 & 1 & 1 & 1 \\
Efficiency & 0.875 & 0.875 & 0.875 & 0.875 & 1 & 0.625 \\
Self-interest & 1 & 1 & 0.750 & 1 & 1 & 0.875 \\
Agreement & 1 & 1 & 1 & 1 & 1 & 1 \\
Questions & 0.875 & 0.875 & 1 & 1 & 1 & 1 \\
General discussion & 1 & 1 & 1 & 1 & 1 & 1 \\
No category & 1 & 1 & 1 & 1 & 0.750 & 1 \\
\hline \hline
\end{tabular}

Notes. The table reports coding where at least three of the four coders agreed. Coders could assign a message to several categories. 
Table D.4: OLS regressions of the proportion of fair products bought on whether or not a consumer sent at least one message belonging to the corresponding category in Switzerland

\begin{tabular}{lccccc}
\hline \hline & $(1)$ & $(2)$ & $(3)$ & $(4)$ & $(5)$ \\
\hline No impact on Cs & 0.048 & & & & \\
& $(0.033)$ & & & & \\
Impact on Cs & & -0.041 & & & \\
& & $(0.066)$ & & & \\
Fairness & & $\left(0.068^{*}\right.$ & & \\
& & & 0.049 & \\
Efficiency & & & $(0.036)$ & \\
& & & & -0.096 \\
Self-interest & & & & $0.068)$ \\
& & & & & \\
Constant & $0.882^{* * *}$ & $0.914^{* * *}$ & $0.873^{* * *}$ & $0.903^{* * *}$ & $0.922^{* * *}$ \\
& $(0.023)$ & $(0.018)$ & $(0.030)$ & $(0.020)$ & $(0.016)$ \\
\hline Observations & 120 & 120 & 120 & 120 & 120 \\
R-squared & 0.017 & 0.003 & 0.034 & 0.010 & 0.029 \\
\hline \hline
\end{tabular}

Notes. The dependent variable in all models is the proportion of fair products bought over the total products bought during the 24 periods; we omit the cases in which the consumer purchased no product. The data concerns the treatments Veil, No Veil and Exclusive. All standard errors (in parentheses) are clustered at the market level, ${ }^{* * *} \mathrm{p}<0.01,{ }^{* *} \mathrm{p}<0.05,{ }^{*} \mathrm{p}<0.1$.

Table D.5: OLS regressions of the proportion of fair products bought on whether or not a consumer sent at least one message belonging to the corresponding category in

China

\begin{tabular}{lccccc}
\hline \hline & $(1)$ & $(2)$ & $(3)$ & $(4)$ & $(5)$ \\
\hline No impact on Cs & $0.179^{* * *}$ & & & & \\
& $(0.063)$ & & & & \\
Impact on Cs & & $-0.130^{*}$ & & & \\
& & $(0.071)$ & & & \\
Fairness & & $0.207^{* * *}$ & & \\
& & $(0.052)$ & & $0.219^{* * *}$ & \\
Efficiency & & & $(0.091)$ & \\
& & & & $-0.141^{*}$ \\
Self-interest & & & & $0.076)$ \\
& & & & & \\
Constant & $0.440^{* * *}$ & $0.509^{* * *}$ & $0.418^{* * *}$ & $0.468^{* * *}$ & $0.522^{* * *}$ \\
& $(0.044)$ & $(0.041)$ & $(0.045)$ & $(0.040)$ & $(0.043)$ \\
\hline Observations & 120 & 120 & 120 & 120 & 120 \\
R-squared & 0.066 & 0.017 & 0.098 & 0.049 & 0.032 \\
\hline \hline
\end{tabular}

Notes. The dependent variable in all models is the proportion of fair products bought over the total products bought during the 24 periods; we omit the cases in which the consumer purchased no product. The data concerns the treatments Veil, No Veil and Exclusive. All standard errors (in parentheses) are clustered at the market level, ${ }^{* * *} \mathrm{p}<0.01,{ }^{* *} \mathrm{p}<0.05,{ }^{*} \mathrm{p}<0.1$. 
Table D.6: OLS regressions of the proportion of fair products bought on the proportion of other participants who sent at least one message belonging to the corresponding category in Switzerland

\begin{tabular}{lccccc}
\hline \hline & $(1)$ & $(2)$ & $(3)$ & $(4)$ & $(5)$ \\
\hline No impact on Cs & -0.090 & & & & \\
& $(0.081)$ & & & & \\
Impact on Cs & & 0.008 & & & \\
& & $(0.151)$ & -0.006 & & \\
Fairness & & $(0.080)$ & & \\
& & & 0.018 & \\
Efficiency & & & $(0.066)$ & 0.089 \\
Self-interest & & & & $(0.180)$ \\
& & & & $0.907 * * *$ & $0.900^{* * *}$ \\
Constant & $0.972^{* * *}$ & $0.910^{* * *}$ & $0.914^{* * *}$ & $0.025)$ \\
& $(0.055)$ & $(0.022)$ & $(0.046)$ & $(0.026)$ & 120 \\
\hline Observations & 120 & 120 & 120 & 120 & 120 \\
R-squared & 0.011 & 0.000 & 0.000 & 0.000 & 0.002 \\
\hline \hline
\end{tabular}

Notes. The dependent variable in all models is the proportion of fair products bought over the total products bought during the 24 periods; we omit the cases in which the consumer purchased no product. The data concerns the treatments Veil, No Veil and Exclusive. All standard errors (in parentheses) are clustered at the market level, ${ }^{* * *} \mathrm{p}<0.01,{ }^{* *} \mathrm{p}<0.05,{ }^{*} \mathrm{p}<0.1$.

Table D.7: OLS regressions of the proportion of fair products bought on the proportion of other participants who sent at least one message belonging to the corresponding category in China

\begin{tabular}{lccccc}
\hline \hline & $(1)$ & $(2)$ & $(3)$ & $(4)$ & $(5)$ \\
\hline No impact on Cs & 0.189 & & & & \\
& $(0.155)$ & & & & \\
Impact on Cs & & -0.242 & & & \\
& & $(0.268)$ & & & \\
Fairness & & 0.302 & & \\
& & $(0.186)$ & & -0.171 & \\
Efficiency & & & $(0.394)$ & \\
Self-interest & & & & $-0.404^{*}$ \\
& & & & $0.207)$ \\
Constant & $0.427^{* * *}$ & $0.531^{* * *}$ & $0.365^{* * *}$ & $0.516^{* * *}$ & $0.590^{* * *}$ \\
& $(0.077)$ & $(0.046)$ & $(0.085)$ & $(0.074)$ & $(0.070)$ \\
\hline Observations & 120 & 120 & 120 & 120 & 120 \\
R-squared & 0.014 & 0.014 & 0.029 & 0.003 & 0.046 \\
\hline \hline
\end{tabular}

Notes. The dependent variable in all models is the proportion of fair products bought over the total products bought during the 24 periods; we omit the cases in which the consumer purchased no product. The data concerns the treatments Veil, No Veil and Exclusive. All standard errors (in parentheses) are clustered at the market level, ${ }^{* * *} \mathrm{p}<0.01,{ }^{* *} \mathrm{p}<0.05,{ }^{*} \mathrm{p}<0.1$. 
Table D.8: OLS regressions of the proportion of fair products offered on whether or not a seller sent at least one message belonging to the corresponding category in Switzerland

\begin{tabular}{lccccc}
\hline \hline & $(1)$ & $(2)$ & $(3)$ & $(4)$ & $(5)$ \\
\hline No impact on Cs & 0.025 & & & & \\
& $(0.031)$ & & & & \\
Impact on Cs & & -0.093 & & & \\
& & $(0.065)$ & 0.032 & & \\
Fairness & & $(0.034)$ & & \\
& & & 0.045 & \\
Efficiency & & & $(0.028)$ & \\
Self-interest & & & & $-0.162^{* * *}$ \\
& & & & & \\
Constant & $0.881^{* * *}$ & $0.904^{* * *}$ & $0.880^{* * *}$ & $0.888^{* * *}$ & $0.915^{* * *}$ \\
& $(0.027)$ & $(0.018)$ & $(0.028)$ & $(0.020)$ & $(0.016)$ \\
\hline Observations & 144 & 144 & 144 & 144 & 144 \\
R-squared & 0.004 & 0.018 & 0.008 & 0.009 & 0.077 \\
\hline \hline
\end{tabular}

Notes. The dependent variable in all models is the proportion of fair products offered over the total products offered during the 24 periods. The data concerns the treatments Veil, No Veil and Exclusive. All standard errors (in parentheses) are clustered at the market level, $* * * \mathrm{p}<0.01$, ** $\mathrm{p}<0.05, * \mathrm{p}<0.1$.

Table D.9: OLS regressions of the proportion of fair products offered on whether or not a seller sent at least one message belonging to the corresponding category in

China

\begin{tabular}{lccccc}
\hline \hline & $(1)$ & $(2)$ & $(3)$ & $(4)$ & $(5)$ \\
\hline No impact on Cs & $0.147^{* *}$ & & & & \\
& $(0.071)$ & & & & \\
Impact on Cs & & -0.069 & & & \\
& & $(0.076)$ & & & \\
Fairness & & $0.190^{* * *}$ & & \\
& & $(0.049)$ & & -0.073 & \\
Efficiency & & & $(0.083)$ & \\
Self-interest & & & & -0.089 \\
& & & & & $0.073)$ \\
Constant & $0.431^{* * *}$ & $0.485^{* * *}$ & $0.400^{* * *}$ & $0.485^{* * *}$ & $0.493 * * *$ \\
& $(0.053)$ & $(0.039)$ & $(0.043)$ & $(0.042)$ & $(0.042)$ \\
\hline Observations & 144 & 144 & 144 & 144 & 144 \\
R-squared & 0.044 & 0.005 & 0.083 & 0.005 & 0.011 \\
\hline \hline
\end{tabular}

Notes. The dependent variable in all models is the proportion of fair products offered over the total products offered during the 24 periods. The data concerns the treatments Veil, No Veil and Exclusive. All standard errors (in parentheses) are clustered at the market level, ${ }^{* * *} \mathrm{p}<0.01, * *$ $\mathrm{p}<0.05,{ }^{*} \mathrm{p}<0.1$. 
Table D.10: OLS regressions of the proportion of fair products offered on the proportion of other participants who sent at least one message belonging to the corresponding category in Switzerland

\begin{tabular}{lccccc}
\hline \hline & $(1)$ & $(2)$ & $(3)$ & $(4)$ & $(5)$ \\
\hline No impact on Cs & -0.104 & & & & \\
& $(0.091)$ & & & & \\
Impact on Cs & & 0.056 & & & \\
& & $(0.175)$ & & & \\
Fairness & & -0.007 & & \\
& & $(0.077)$ & & 0.009 & \\
Efficiency & & & $(0.062)$ & 0.000 \\
Self-interest & & & & $0.210)$ \\
& & & & & \\
Constant & $0.967^{* * *}$ & $0.892^{* * *}$ & $0.901^{* * *}$ & $0.895^{* * *}$ & $0.897 * * *$ \\
& $(0.061)$ & $(0.023)$ & $(0.045)$ & $(0.025)$ & $(0.026)$ \\
\hline Observations & 144 & 144 & 144 & 144 & 144 \\
R-squared & 0.015 & 0.001 & 0.000 & 0.000 & 0.000 \\
\hline \hline
\end{tabular}

Notes. The dependent variable in all models is the proportion of fair products offered over the total products offered during the 24 periods. The data concerns the treatments Veil, No Veil and Exclusive. All standard errors (in parentheses) are clustered at the market level, ${ }^{* * *} \mathrm{p}<0.01, * *$ $\mathrm{p}<0.05,{ }^{*} \mathrm{p}<0.1$.

Table D.11: OLS regressions of the proportion of fair products offered on the proportion of other participants who sent at least one message belonging to the corresponding category in Switzerland

\begin{tabular}{|c|c|c|c|c|c|}
\hline & (1) & (2) & (3) & (4) & (5) \\
\hline No impact on Cs & $\begin{array}{c}0.213 \\
(0.158)\end{array}$ & & & & \\
\hline Impact on Cs & & $\begin{array}{l}-0.329 \\
(0.249)\end{array}$ & & & \\
\hline Fairness & & & $\begin{array}{l}0.322 * \\
(0.183)\end{array}$ & & \\
\hline Efficiency & & & & $\begin{array}{l}-0.020 \\
(0.357)\end{array}$ & \\
\hline Self-interest & & & & & $\begin{array}{c}-0.442 * * \\
(0.213)\end{array}$ \\
\hline Constant & $\begin{array}{c}0.401^{* * *} \\
(0.077)\end{array}$ & $\begin{array}{c}0.527 * * * \\
(0.043)\end{array}$ & $\begin{array}{c}0.339 * * * \\
(0.088)\end{array}$ & $\begin{array}{c}0.479 * * * \\
(0.070)\end{array}$ & $\begin{array}{c}0.583^{* * * *} \\
(0.070)\end{array}$ \\
\hline Observations & 144 & 144 & 144 & 144 & 144 \\
\hline R-squared & 0.016 & 0.026 & 0.032 & 0.000 & 0.055 \\
\hline
\end{tabular}

Notes. The dependent variable in all models is the proportion of fair products offered over the total products offered during the 24 periods. The data concerns the treatments Veil, No Veil and Exclusive. All standard errors (in parentheses) are clustered at the market level, ${ }^{* * *} \mathrm{p}<0.01$, ** $\mathrm{p}<0.05,{ }^{*} \mathrm{p}<0.1$. 


\section{E. Content Analysis for Study 2}

Table E.1: Different coding categories and their description

\begin{tabular}{|c|c|}
\hline Category & Description \\
\hline $\begin{array}{l}\text { Recommending no } \\
\text { impact on the } \\
\text { donation }\end{array}$ & $\begin{array}{l}\text { Any statement supporting the exchange of the "products with no effect } \\
\text { on the donation", or the boycott of the "products with a reduction for } \\
\text { the donation," irrespective of whether or not a reason is given. Note that } \\
\text { the statements can be explicit or implicit. }\end{array}$ \\
\hline $\begin{array}{l}\text { Recommending } \\
\text { impact on Cs }\end{array}$ & $\begin{array}{l}\text { Any statement supporting the exchange of the "products with a } \\
\text { reduction for the donation," irrespective of whether or not a reason is } \\
\text { given. Note that the statements can be explicit or implicit. }\end{array}$ \\
\hline $\begin{array}{l}\text { Discussion of } \\
\text { prices }\end{array}$ & $\begin{array}{l}\text { Any statement mentioning or discussing the prices of the products } \\
\text { exchanged. }\end{array}$ \\
\hline Fairness & $\begin{array}{l}\text { Any statement supporting an argument by appealing to fairness, the } \\
\text { "right thing to do" or morality, or demonstrating some concern for the } \\
\text { environment and/or poverty. }\end{array}$ \\
\hline Efficiency & $\begin{array}{l}\text { Any statement supporting an argument by appealing to efficiency } \\
\text { (maximizing the total earnings of everybody), sustainability, or } \\
\text { comparing the cost of having no impact on the donation with the loss } \\
\text { incurred by the donation. }\end{array}$ \\
\hline Self-interest & $\begin{array}{l}\text { Any statement supporting an argument by appealing to selfishness, } \\
\text { maximization of own profit or earnings. }\end{array}$ \\
\hline Agreement & Any statement agreeing with or supporting a previous argument. \\
\hline $\begin{array}{l}\text { Mentioning } \\
\text { COTAP and/or its } \\
\text { purposes }\end{array}$ & $\begin{array}{l}\text { Any statement that mentions or discusses the charity (COTAP) and/or } \\
\text { its objective to fight climate change and poverty. It can be any statement } \\
\text { that expresses support or aversion for the charity, irrespective of } \\
\text { whether or not a reason is given. }\end{array}$ \\
\hline $\begin{array}{l}\text { Referring to past } \\
\text { behavior }\end{array}$ & $\begin{array}{l}\text { Any statement referring to past behavior to justify supporting either no } \\
\text { impact or impact on the donation. }\end{array}$ \\
\hline $\begin{array}{l}\text { Questions about } \\
\text { what to do in the } \\
\text { market game }\end{array}$ & $\begin{array}{l}\text { Any statement questioning what participants should do in the market } \\
\text { game, in the form of a question or not. }\end{array}$ \\
\hline $\begin{array}{l}\text { General discussion } \\
\text { of the game or the } \\
\text { experiment }\end{array}$ & $\begin{array}{l}\text { Any statement that mentions or discusses the market game or the } \\
\text { experiment without clearly prescribing, supporting or justifying any } \\
\text { particular behavior. }\end{array}$ \\
\hline $\begin{array}{l}\text { No category/ } \\
\text { Unclear }\end{array}$ & $\begin{array}{l}\text { Any statement that does not fit in any category or for which the meaning } \\
\text { is unclear. Use this category for any messages that you cannot } \\
\text { otherwise categorize. You should not use this category if you also } \\
\text { assign another category to a message. }\end{array}$ \\
\hline
\end{tabular}


Table E.2: Fraction of messages assigned to each category

\begin{tabular}{lcc}
\hline \hline & $\begin{array}{c}\text { Exclusive } \\
\text { (Charity) }\end{array}$ & $\begin{array}{c}\text { Experienced } \\
\text { (Charity) }\end{array}$ \\
\hline No impact on the donation & 0.17 & 0.17 \\
Impact on the donation & 0.03 & 0.04 \\
Prices & 0.15 & 0.20 \\
Fairness & 0.09 & 0.11 \\
Efficiency & 0.03 & 0.05 \\
Self-interest & 0.02 & 0.02 \\
Agreement & 0.20 & 0.19 \\
COTAP & 0.01 & 0.02 \\
Past behavior & 0.00 & 0.01 \\
Questions & 0.09 & 0.06 \\
General discussion & 0.10 & 0.08 \\
No category & 0.19 & 0.19 \\
\hline \hline
\end{tabular}

Notes. The table reports coding where at least three of the four coders agreed. Coders could assign a message to several categories.

Table E.3: Fraction of markets in which at least one message belongs to a category

\begin{tabular}{lcc}
\hline \hline & $\begin{array}{c}\text { Exclusive } \\
\text { (Charity) }\end{array}$ & $\begin{array}{c}\text { Experienced } \\
\text { (Charity) }\end{array}$ \\
\hline No impact on the donation & 0.938 & 0.938 \\
Impact on the donation & 0.750 & 0.688 \\
Prices & 1 & 0.938 \\
Fairness & 0.875 & 1 \\
Efficiency & 0.875 & 0.938 \\
Self-interest & 0.563 & 0.625 \\
Agreement & 1 & 1 \\
COTAP & 0.375 & 0.563 \\
Past behavior & - & 0.313 \\
Questions & 1 & 1 \\
General discussion & 1 & 0.938 \\
No category & 0.813 & 0.878 \\
\hline \hline
\end{tabular}

Notes. The table reports coding where at least three of the four coders agreed. Coders could assign a message to several categories. 
Table E.4: OLS regressions of the proportion of fair products bought on whether or not a consumer sent at least one message belonging to the corresponding category

\begin{tabular}{|c|c|c|c|c|c|}
\hline & (1) & (2) & (3) & (4) & (5) \\
\hline No impact on Cs & $\begin{array}{c}0.215^{* * *} \\
(0.042)\end{array}$ & & & & \\
\hline Impact on Cs & & $\begin{array}{c}-0.294 * * * \\
(0.062)\end{array}$ & & & \\
\hline Fairness & & & $\begin{array}{c}0.056 \\
(0.057)\end{array}$ & & \\
\hline Efficiency & & & & $\begin{array}{c}0.079 \\
(0.056)\end{array}$ & \\
\hline Self-interest & & & & & $\begin{array}{c}-0.245^{* * * *} \\
(0.077)\end{array}$ \\
\hline Constant & $\begin{array}{c}0.673^{* * *} \\
(0.042)\end{array}$ & $\begin{array}{c}0.818 * * * \\
(0.034)\end{array}$ & $\begin{array}{c}0.755^{* * * *} \\
(0.046)\end{array}$ & $\begin{array}{c}0.760^{* * *} \\
(0.037)\end{array}$ & $\begin{array}{c}0.802^{* * *} \\
(0.036)\end{array}$ \\
\hline Observations & 160 & 160 & 160 & 160 & 160 \\
\hline R-squared & 0.110 & 0.105 & 0.007 & 0.009 & 0.057 \\
\hline
\end{tabular}

Notes. The dependent variable in all models is the proportion of fair products bought over the total products bought during the last 16 periods; we omit the cases in which the consumer purchased no product. The data concerns the treatments Discourse (Before) and Discourse (Intermediate). All standard errors (in parentheses) are clustered at the market level, $* * *$ $\mathrm{p}<0.01,{ }^{* *} \mathrm{p}<0.05,{ }^{*} \mathrm{p}<0.1$.

Table E.5: OLS regressions of the proportion of fair products bought on the proportion of other participants who sent at least one message belonging to the corresponding category

\begin{tabular}{|c|c|c|c|c|c|}
\hline & (1) & $(2)$ & (3) & (4) & (5) \\
\hline No impact on Cs & $\begin{array}{c}0.251^{* * *} \\
(0.121)\end{array}$ & & & & \\
\hline Impact on Cs & & $\begin{array}{c}-0.904 * * * \\
(0.168)\end{array}$ & & & \\
\hline Fairness & & & $\begin{array}{c}-0.052 \\
(0.183)\end{array}$ & & \\
\hline Efficiency & & & & $\begin{array}{c}0.170 \\
(0.211)\end{array}$ & \\
\hline Self-interest & & & & & $\begin{array}{c}-0.907 * * \\
(0.401)\end{array}$ \\
\hline Constant & $\begin{array}{c}0.641^{* * *} \\
(0.078)\end{array}$ & $\begin{array}{c}0.885^{* * *} \\
(0.039)\end{array}$ & $\begin{array}{c}0.792 * * * \\
(0.070) \\
\end{array}$ & $\begin{array}{c}0.740 * * * \\
(0.059)\end{array}$ & $\begin{array}{c}0.849 * * * \\
(0.042)\end{array}$ \\
\hline Observations & 160 & 160 & 160 & 160 & 160 \\
\hline R-squared & 0.044 & 0.131 & 0.001 & 0.007 & 0.067 \\
\hline
\end{tabular}

Notes. The dependent variable in all models is the proportion of fair products bought over the total products bought during the last 16 periods; we omit the cases in which the consumer purchased no product. The data concerns the treatments Discourse (Before) and Discourse (Intermediate). All standard errors (in parentheses) are clustered at the market level, *** $\mathrm{p}<0.01,{ }^{* *} \mathrm{p}<0.05, * \mathrm{p}<0.1$. 
Table E.6: OLS regressions of the proportion of fair products offered on whether or not a seller sent at least one message belonging to the corresponding category

\begin{tabular}{|c|c|c|c|c|c|}
\hline & (1) & $(2)$ & (3) & (4) & (5) \\
\hline No impact on Cs & $\begin{array}{c}0.185 * * * \\
(0.061)\end{array}$ & & & & \\
\hline Impact on Cs & & $\begin{array}{c}-0.390 * * * \\
(0.089)\end{array}$ & & & \\
\hline Fairness & & & $\begin{array}{c}0.069 \\
(0.063)\end{array}$ & & \\
\hline Efficiency & & & & $\begin{array}{c}0.074 \\
(0.059)\end{array}$ & \\
\hline Self-interest & & & & & $\begin{array}{c}-0.278 * * \\
(0.114)\end{array}$ \\
\hline Constant & $\begin{array}{c}0.666 * * * \\
(0.054)\end{array}$ & $\begin{array}{c}0.812^{* * *} \\
(0.033)\end{array}$ & $\begin{array}{c}0.749 * * * \\
(0.043)\end{array}$ & $\begin{array}{c}0.755^{* * *} \\
(0.040)\end{array}$ & $\begin{array}{c}0.789 * * * \\
(0.035)\end{array}$ \\
\hline Observations & 192 & 192 & 192 & 192 & 192 \\
\hline R-squared & 0.070 & 0.119 & 0.009 & 0.008 & 0.038 \\
\hline
\end{tabular}

Notes. The dependent variable in all models is the proportion of fair products offered over the total products bought during the last 16 periods. The data concerns the treatments Discourse (Before) and Discourse (Intermediate). All standard errors (in parentheses) are clustered at the market level, ${ }^{* * *} \mathrm{p}<0.01,{ }^{* *} \mathrm{p}<0.05,{ }^{*} \mathrm{p}<0.1$.

Table E.7: OLS regressions of the proportion of fair products bought on the proportion of other participants who sent at least one message belonging to the corresponding category

\begin{tabular}{|c|c|c|c|c|c|}
\hline & (1) & (2) & (3) & (4) & (5) \\
\hline No impact on Cs & $\begin{array}{c}0.290^{* * *} \\
(0.127)\end{array}$ & & & & \\
\hline Impact on Cs & & $\begin{array}{c}-0.855^{* * *} \\
(0.163)\end{array}$ & & & \\
\hline Fairness & & & $\begin{array}{l}-0.011 \\
(0.177)\end{array}$ & & \\
\hline Efficiency & & & & $\begin{array}{c}0.132 \\
(0.203)\end{array}$ & \\
\hline Self-interest & & & & & $\begin{array}{c}-0.865 * * \\
(0.398)\end{array}$ \\
\hline Constant & $\begin{array}{c}0.621^{* * * *} \\
(0.080)\end{array}$ & $\begin{array}{c}0.880 * * * \\
(0.040)\end{array}$ & $\begin{array}{c}0.775 * * * \\
(0.071)\end{array}$ & $\begin{array}{c}0.745 * * * \\
(0.056)\end{array}$ & $\begin{array}{c}0.847 * * * \\
(0.044)\end{array}$ \\
\hline Observations & 192 & 192 & 192 & 192 & 192 \\
\hline R-squared & 0.049 & 0.109 & 0.000 & 0.004 & 0.058 \\
\hline
\end{tabular}

Notes. The dependent variable in all models is the proportion of fair products offered over the total products bought during the last 16 periods. The data concerns the treatments Discourse (Before) and Discourse (Intermediate). All standard errors (in parentheses) are clustered at the market level, ${ }^{* * *} \mathrm{p}<0.01,{ }^{* *} \mathrm{p}<0.05,{ }^{*} \mathrm{p}<0.1$. 


\section{F. Instructions for Study 1}

\section{F.1 Market Game}

We are pleased to welcome you to this economic study. If you read the following instructions carefully, you can - depending on your decisions and/or those of the other participants - earn money in addition to the 15 Swiss francs that you receive as an initial endowment for participating. It is thus very important that you read the instructions carefully. If you have any questions, please contact us.

Communication with the other participants is strictly forbidden during the study. Violation of this rule will lead to exclusion from the study and loss of all of the associated payments.

During the study, we will not speak of francs, but of points. Your entire income will thus first be calculated in points. The points you earn during the study will be converted to Swiss francs at the end of the study. The following conversion rate applies: 10 points $=$ CHF 2.50 .

At the end of today's study, you will receive the number of points earned during the study plus the initial endowment of 15 Swiss francs for appearing in cash. We will explain the exact procedure of the study on the next pages. For the sake of simplicity, we will always use male forms for participants; the instructions also obviously refer to female participants.

\section{The study}

There are three types of participants in this study: participants $A, B$, and $C$. The participants in this study are divided into groups of 16 people. There are 6 participants A, 5 participants $B$, and 5 participants $C$ in each group.

Participants A are sellers, participants B are buyers. Participants $C$ can neither sell nor buy, but they can incur losses due to the transactions between the participants $A$ and $B$.

The study last for 24 periods. In each period, each participant A makes exactly one sales offer for a product. Participant A thereby determines the type of product and the price for the product.

- There are two types of products:

1. "Products with no effect on participant $C$ " and

2. "Products with a loss for participant $C$ ".

- Every value from 0 up to and including 50 can be selected as a price.

The production costs for participants A for a "product with no effect on participant $C$ " amount to 10 points. Participant A bears no costs (0 points) for the production of a "product with a loss for participant $C^{\prime}$.

The value of a product for a participant $B$ is always 50 points, regardless of what type of product it is. 
The five participants B see the sales offers made by the six participants A (the price and the type of product) and can accept one offer each. The participants $B$ can decide one after the other in a random order. Each participant B can only accept one offer. This means that a maximum of five of the six participants A can sell a product.

In each period, each of the five participants $B$ will be randomly assigned to one of the five participants C. If a participant $B$ purchases a "product with a loss for participant $C$ ", the assigned participant $C$ incurs a loss of 60 points. If a participant $B$ purchases a "product with no effect on participant $C$ " or no product at all, the assigned participant $C$ incurs no loss.

You will see whether you are participant $A, B$, or $C$ on your screen at the beginning of the study. Your role as participant $A, B$, or $C$ remains the same during the entire study.

In each period, each participant $A, B$, and $C$ first receives an endowment of 100 points. The payment in points of participant $A$ (seller), participant $B$ (buyer), and participant $C$ in a period are thus determined as follows:

Participant A's payment

- If a participant B accepts his sales offer: 100 - production cost + price of the product where the production cost amounting to 10 points are incurred only with a "product without effect on participant $C$ ". The production costs for a "product with a loss for participant $C$ amount to 0 .

- If no participant B accepts his sales offer: 100

Participant B's payment:

- If participant B accepts a sales offer: $100+50$ - price of the product

- If participant $B$ does not accept a sales offer: 100

Participant C's payment:

- If the randomly assigned participant B chooses a "Product with loss for participant C:" 100 $-60=40$

- If the randomly assigned participant B chooses a "Product without effect on participant C" or does not purchase a product: 100 


\section{Procedures on the computer:}

In each period, participants A enter their sales offers on the following screen:

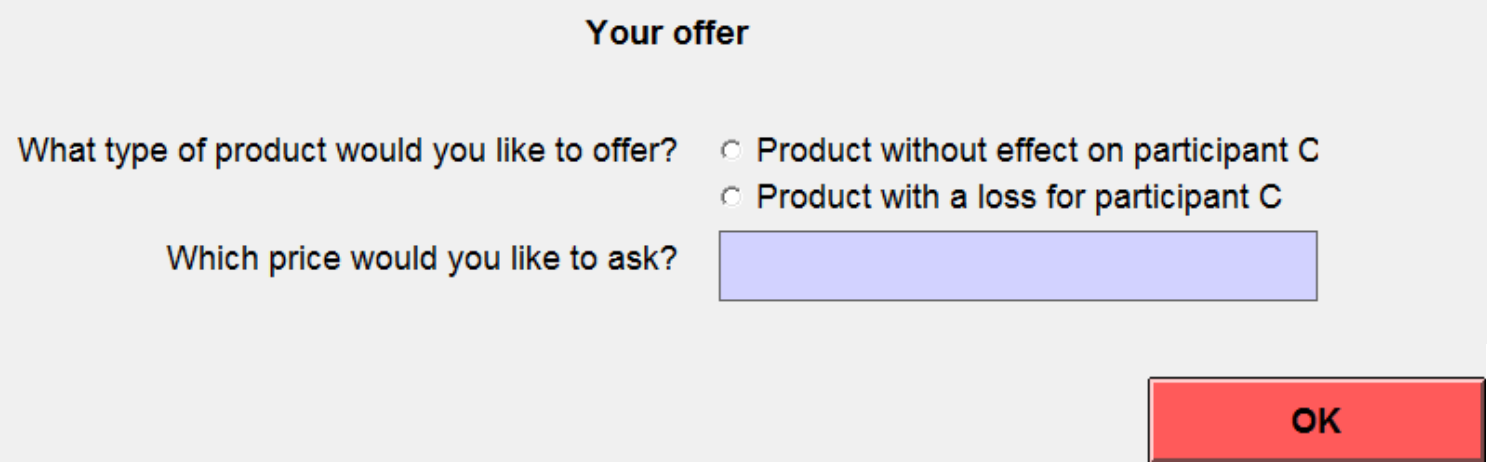

Participant A must indicate whether he wants to offer a "product without effect on participant C" or a "product with a loss for participant C." to do this, the corresponding type of product must be clicked on.

Furthermore, participant A must indicate the price he wants to request for the product. The corresponding number must be entered in the box. All integers from 0 up to and including 50 are possible.

Once a participant A has made his decisions, he must click on the OK button at the lower righthand side. The type of product and the price can be changed until the OK button is clicked.

Once all six participants A have made their sales offers, the participants A will see the sales offers (the price and the type of product) of all of the other participants A in a table. Here is an example:

\begin{tabular}{|c|c|c|}
\hline Price of the product & Type of the product & Order of acceptance \\
\hline $\begin{array}{c}\text { This is where the participants } A \\
\text { see the price of the product for } \\
\text { every sales offer }\end{array}$ & $\begin{array}{c}\text { This is where the participants } A \\
\text { see the type of product for } \\
\text { every sales offer }\end{array}$ & $\begin{array}{c}\text { accepted SECOND } \\
- \\
\text { accepted FIRST } \\
-\end{array}$ \\
\hline
\end{tabular}

The participant's own sales offer is always marked in blue. Participants A can always see in the column on the right whether and in which order the participants $B$ accept the offers.

Once all participants $B$ have made their decisions, each participant $A$ will learn of his own payment. If his offer is accepted, participant A will also learn participant B's payment and the payment of the corresponding participant $C$. 
The participants B can see the sales offers on the screen below in each period:

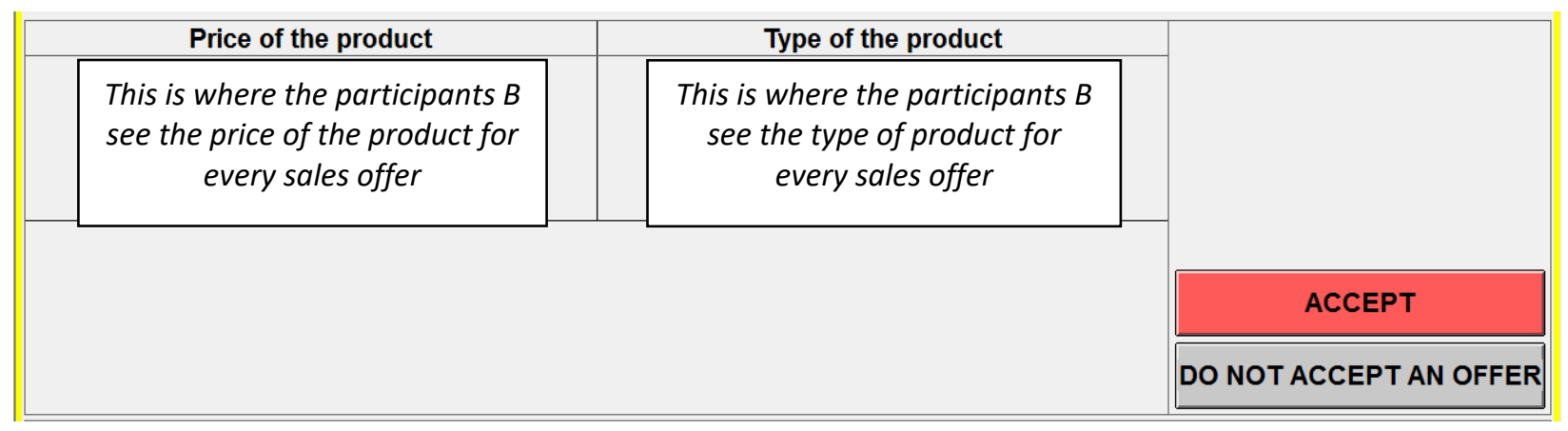

Participants B see the screen above in a random order and can accept an offer one after the other. Thus only one participant B sees the screen above at any one point in time. Only when the current participant $B$ has made his decisions will the next participant $B$ see the screen above, where he can then accept an offer.

The participant $B$ who is first shown the screen can select from all offers. The participant $B$ who is shown the screen second can only choose from the remaining offers, as each offer can only be accepted by one participant $B$.

If the five participants $B$ have each accepted an offer, one offer will always remain that can no longer be accepted. The participant $A$ who made this offer cannot conclude a sale in this period.

The order in which the five participants $B$ decide on accepting the six offers will be randomly determined anew in each period.

The prices appear in the left column of the table, and the type of product appears in the right column. Each offer is always in a separate row. In order to accept an offer, the corresponding row must be clicked on with the mouse. The marked row will then appear with a blue background.

In order to accept the offer marked in blue, you must click on the ACCEPT button.

The choice of offer can be changed until the ACCEPT button is clicked on.

If a participant B does not want to accept an offer, he must click on the DO NOT ACCEPT AN OFFER button. Even if a row had already been marked, all offers will be declined if the DO NOT ACCEPT AN OFFER is clicked on.

When all participants $B$ have made their decisions, each participant $B$ will learn of his own payment and that of his assigned participant $C$. 
Participants $C$ cannot make any decisions during this study. We ask the participants $C$, however, to indicate in each period their expectations about the behaviors of participants $A$ and $B$.

When all participants $A$ and $B$ have made their decisions, the participants $C$ will learn of their own earnings, which are entirely dependent on the decisions of participants $A$ and $B$.

After all participants have been informed about their payments in a period, the next period will begin.

Your earnings in this study are the payment out of one randomly selected period.

Because you do not know which period the computer will randomly select, you must consider your decisions in each of the 24 periods very carefully.

At the end of the study, the corresponding point amount will be converted to Swiss francs and paid in cash to you together with the initial endowment.

Do you have any further questions? If yes, please raise your hand. We will come to you at your workplace. Otherwise, we ask you to answer the control questions on the next pages.

\section{Control questions}

1. Assume that participant A offers a "product without effect on participant $C$ " at the price of 40 and participant $B$ accepts the offer.

How high are the payments to participants $A$ and $B$ and the corresponding participant $C$ ?

2. Assume that participant A offers a "product with a loss for participant $C$ " at the price of 40 and participant $B$ accepts the offer.

How high are the payments to participants $A$ and $B$ and the corresponding participant $C$ ?

3. Assume that participant A offers a "product without effect on participant $C$ " at the price of 15 and participant $B$ accepts the offer.

How high are the payments to participants $A$ and $B$ and the corresponding participant $C$ ?

4. Assume that participant A offers a "product with a loss for participant $C$ " at the price of 15 and no participant $B$ accepts the offer.

How high is the payment for participant A? How high is the payment for a participant $B$ who does not accept an offer? How high is the payment for the corresponding participant $C$ ?

Please raise your hand when you have completed the control questions. We will then come to you at your workplace. 


\section{F.2 Debate}

The instructions are shown on the screen after subjects read the instructions and but before they entered the market game. In the following, we provide the instructions are for condition No Veil. The instructions for conditions Veil and Exclusive are identical, except that the subjects are not informed about their role on Screen 1 (in Veil) or that participants A and B are informed that participants C will communicate separately (in Exclusive).

\section{Screen 1}

You are a participant A (seller) / participant B (buyer) / participant C for the entire duration of the study.

Participants C only: We know that this role might be not satisfying! For scientific reasons it is however necessary that participants $C$ participate in this study. We very much hope for your understanding.

\section{Screen 2}

Before we begin with the study, the 16 participants who will make up a group of 6 players As, 5 player Bs and 5 player Cs will have the opportunity to communicate with each other through a discussion board.

During this time, we ask you to discuss with the other participants how "socially acceptable" or "socially inacceptable" it is to trade the "product with a loss for participant C." That is, as a buyer or seller, to what extent is trading this product consistent or inconsistent with what most people agree is the "appropriate," "right" or "moral" thing to do?

You have eight minutes to discuss with the other participants in your group. Please use this time to discuss this topic.

Please click the "next"-button to get to the chat page.

\section{Screen 3}

Please enter your messages in the blue box at the bottom of the page. After typing in your message to the other participants, please press the "Enter" key to display your message. Each participant has been assigned a random number, which is displayed in front of the respective messages. This number is displayed along with the corresponding participant's role (A, B, or $C$ ). You see your number when you enter your first message. This number is simply so that you can keep track of each other during the discussion. Afterward, you will not see or use these numbers. Please refrain from sending any messages that could personally identify you.

You are a participant A/B/C. Participants A are sellers, Participants $B$ are buyers. Participants $C$ can incur losses due to the transactions between the participants $A$ and $B$.

\section{Screen 4}

Thank you very much for taking part in the discussion. 


\section{F.3 Norm Elicitation}

\section{Screen 1}

Thank you very much for taking part in the study. We now ask you to rate how "socially acceptable" or "socially inacceptable" it is to trade the "product with a loss for participant C." That is, as a buyer or seller, to what extent is trading this product consistent or inconsistent with what most people agree is the "appropriate," "right" or "moral" thing to do? You may choose from four possible responses: "highly socially acceptable," "somewhat socially acceptable," "somewhat socially inacceptable," and "highly socially inacceptable."

The rating you provide affects how much money you earn today. Specifically, we are going to ask you to match your rating to those of the participants in your group with which you interacted in the main part of the study. Note that we do not ask you to provide the rating you believe to be "right" but the rating you believe will be the one most frequently chosen in your group.

At the end of the study today, we will find out which response was selected by the most people in your group. If you give the same response as that most frequently given by the participants in your group, then you will receive an additional CHF 10 (on top of your earnings from the main part of the study). Otherwise you would receive no additional money. The amount you earn from both parts of the study will be paid to you, in cash, at the conclusion of the study.

For instance, suppose that you respond "highly socially inacceptable," then you would receive an additional CHF 10 if the most common response in your group is also "highly socially inacceptable," but you receive CHF 0 if the most common response is something else. Similarly, if you respond, for example, "somewhat socially acceptable," then you would receive an additional CHF 10 if the most common response in your group is also "somewhat socially acceptable," but you receive CHF 0 if the most common response is something else.

If you have any questions, please raise your hand.

\section{Screen 2}

Below, please provide your rating of how socially acceptable or socially inacceptable it is to trade the "product with a loss for participant C." You may provide your rating by placing a check mark in the corresponding box and then confirming this choice.

Recall that you earn additional money if you give the same response as that most frequently selected by the other participants in the group. Specifically, if you match the most common answer in your group, then you will receive an additional CHF 10.

What do you think is the most commonly selected answer? Trading the "product with a loss for participant C" is: Highly socially acceptable / Somewhat socially acceptable / Somewhat socially inacceptable / Highly socially inacceptable

\section{Screen 3}

The most common response in your group is that trading the product with a loss for participant $C$ is: [result here]. Your response was that trading the product with a loss for participant $C$ is: [choice here] Your rating did match the most frequently selected rating. Hence you earn an additional 10 CHF. / Your rating did not match the most frequently selected rating. Hence you do not earn an additional $10 \mathrm{CHF}$. 


\section{G. Instructions for Study 2}

\section{G.1 Market Game}

\section{The study}

There are two types of participants in this study: Participants A and B. The participants are divided into groups of 11 people. There are six Participants $A$ and five Participants $B$ (buyers) in each group. Participants A are sellers and Participants $B$ are buyers. You will see whether you are Participant A or B on your screen at the beginning of the study. Your role as Participant A or B will remain the same during the entire study.

For each participant B, a donation to the charity COTAP of potentially 100 points (25 CHF) will be made. The organization COTAP (Carbon Offsets To Alleviate Poverty) supports certified forestry projects in under-developed countries, which help reduce $\mathrm{CO}_{2}$ in the atmosphere and create life-changing income for the world's poorest people. More details about COTAP's mission are provided at the end of the instructions. The exact amount of the donation to COTAP depends on what type of product a seller (Participant A) and buyer (Participant B) trade. This will be explained in more detail below.

The study last for 24 periods. In each period, each participant A makes exactly one sales offer for a product. Participant A thereby determines the type of product and the price for the product.

- $\quad$ There are two types of products:

1. "Products with no effect on the donation" and

2. "Products with a reduction for the donation".

- Every value from 0 up to and including 50 can be selected as a price.

Production cost:

- The production costs for participants A for a "product with no effect on the donation" amount to 20 points. Participant A bears no costs ( 0 points) for the production of a "product with a reduction for the donation".

Value of the product:

- The value of a product for a participant B is always 50 points, regardless of what type of product it is.

Effect on the donation:

- If a participant B purchases a "product with no effect on the donation" or no product at all, the donation will be not be reduced and will be of 100 points.

- If a participant $B$ purchases a "product with a reduction for the donation", the donation will incur a reduction of 60 points to 40 points. 


\section{Market Activity}

The five participants $B$ see the sales offers made by the six participants $A$ (the price and the type of product) and can accept one offer each. The participants $B$ can decide one after the other in a random order. Each participant $B$ can only accept one offer. This means that a maximum of five of the six participants A can sell a product.

\section{Payment}

In each period, each Participant $A$ and Participant B initially receives an endowment of 100 points. The payments in points of Participant A (seller) and Participant B (buyer) in a period are then determined as follows:

\section{Participant A's payment}

- If a participant B accepts his sales offer: 100 - production cost + price of the product where the production cost amounting to 20 points are incurred only with a "product without effect on the donation". The production costs for a "product with a reduction for the donation" amount to 0 .

- If no participant B accepts his sales offer: 100

Participant B's payment:

- If participant B accepts a sales offer: $100+50$ - price of the product

- If participant $B$ does not accept a sales offer: 100

Amount donated by Participant B:

- If a participant B chooses a "Product with reduction for the donation:" 100 - 60

- If a participant B chooses a "Product without effect on the donation" or does not purchase a product: 100

\section{More about COTAP:}

The mission of COTAP is to empower individuals and organizations in developed countries to address both climate change and global poverty. COTAP counteracts carbon emissions through certified forestry projects in under-developed regions, which create transparent, accountable, and life-changing earnings for rural farming communities where income levels are less than \$2 per day. 
COTAP sources carbon offset funds from those who care about both climate change and poverty alleviation, pools those funds, and transparently matches those funds with their partners' forestry projects in order to fill the forestry carbon finance gap, restore landscapes, and create direct, significant, verifiable, and lasting benefits for the most economically vulnerable people in the world.

Through COTAP, you are paying smallholder farmers in developing countries for planting and maintaining trees, which capture and store your CO2 emissions. A donation of 10 points (= CHF 2.5) offsets 0.25 tons of carbon dioxide $\left(\mathrm{CO}_{2}\right)$, or $250 \mathrm{Kg}$ of $\mathrm{CO}_{2}$.

\section{Procedures on the computer:}

In each period, participants A enter their sales offers on the following screen:

\section{Your offer}

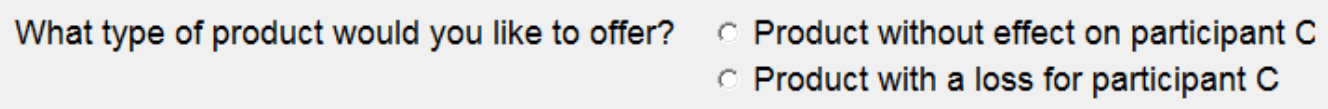

Participant A must indicate whether he wants to offer a "product without effect on the donation" or a "product with a reduction for the donation." to do this, the corresponding type of product must be clicked on.

Furthermore, participant A must indicate the price he wants to request for the product. The corresponding number must be entered in the box. All integers from 0 up to and including 50 are possible.

Once a participant A has made his decisions, he must click on the OK button at the lower righthand side. The type of product and the price can be changed until the OK button is clicked.

Once all six participants A have made their sales offers, the participants A will see the sales offers (the price and the type of product) of all of the other participants A in a table. Here is an example:

\begin{tabular}{|c|c|c|}
\hline Price of the product & Type of the product & Order of acceptance \\
\hline $\begin{array}{c}\text { This is where the participants } A \\
\text { see the price of the product for } \\
\text { every sales offer }\end{array}$ & $\begin{array}{c}\text { This is where the participants } A \\
\text { see the type of product for } \\
\text { every sales offer }\end{array}$ & $\begin{array}{c}\text { accepted SECOND } \\
- \\
\text { accepted FIRST } \\
-\end{array}$ \\
\hline
\end{tabular}

The participant's own sales offer is always marked in blue. Participants A can always see in the column on the right whether and in which order the participants $B$ accept the offers. 
Once all participants $B$ have made their decisions, each participant $A$ will learn of his own payment. If his offer is accepted, participant A will also learn participant B's payment and the corresponding amount donated.

The participants B can see the sales offers on the screen below in each period:

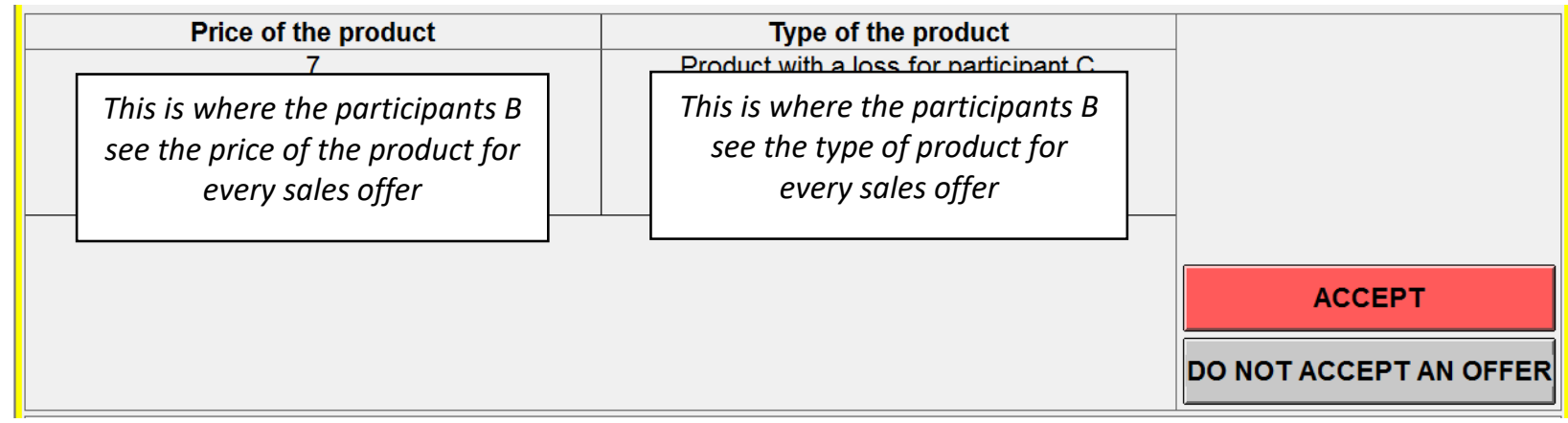

Participants B see the screen above in a random order and can accept an offer one after the other. Thus only one participant B sees the screen above at any one point in time. Only when the current participant $B$ has made his decisions will the next participant $B$ see the screen above, where he can then accept an offer.

The participant $B$ who is first shown the screen can select from all offers. The participant $B$ who is shown the screen second can only choose from the remaining offers, as each offer can only be accepted by one participant $B$.

If the five participants $B$ have each accepted an offer, one offer will always remain that can no longer be accepted. The participant A who made this offer cannot conclude a sale in this period.

The order in which the five participants $B$ decide on accepting the six offers will be randomly determined anew in each period.

The prices appear in the left column of the table, and the type of product appears in the right column. Each offer is always in a separate row. In order to accept an offer, the corresponding row must be clicked on with the mouse. The marked row will then appear with a blue background.

In order to accept the offer marked in blue, you must click on the ACCEPT button.

The choice of offer can be changed until the ACCEPT button is clicked on.

If a participant $B$ does not want to accept an offer, he must click on the DO NOT ACCEPT AN OFFER button. Even if a row had already been marked, all offers will be declined if the DO NOT ACCEPT AN OFFER is clicked on.

When all participants $B$ have made their decisions, each participant $B$ will learn of his own payment and the corresponding amount donated.

After all participants have been informed about their payments and the amount donated in a period, the next period will begin. 
Your earnings in this study are the payment out of one randomly selected period. This selected period will also determine the actual donation that is made to COTAP.

Because you do not know which period the computer will randomly select, you must consider your decisions in each of the 24 periods very carefully.

At the end of the study, the corresponding point amount will be converted to Swiss francs and paid in cash to you together with the initial endowment.

We will also make the donation to COTAP. If you want to verify that COTAP actually received the money donated, you will be prompted to type in your e-mail address at the end of the study and we will send you a dated receipt indicating the donated amount.

Do you have any further questions? If yes, please raise your hand. We will come to you at your workplace. Otherwise, we ask you to answer the control questions on the next pages.

\section{Control questions}

1. Assume that participant A offers a "product without effect on the donation" at the price of 40 and participant $B$ accepts the offer.

How high are the payments to participants A and B and the corresponding amount donated?

2. Assume that participant A offers a "product with a reduction for the donation" at the price of 40 and participant $B$ accepts the offer.

How high are the payments to participants A and B and the corresponding amount donated?

3. Assume that participant A offers a "product without effect on the donation" at the price of 25 and participant $B$ accepts the offer.

How high are the payments to participants $A$ and $B$ and the corresponding amount donated?

4. Assume that participant A offers a "product with a reduction for the donation" at the price of 25 and no participant $B$ accepts the offer.

How high is the payment for participant A? How high is the payment for a participant $B$ who does not accept an offer? How high is the corresponding amount donated?

\section{G.2 Debate}

Instructions correspond to the ones in Study 1, which the respective changes implemented.

\section{G.3 Norm Elicitation}

Instructions correspond to the ones in Study 1, which the respective changes implemented. 